\title{
Mountain building in Taiwan: A thermokinematic model
}

\author{
Martine Simoes, ${ }^{1,2,3}$ Jean Philippe Avouac, ${ }^{1}$ Olivier Beyssac, ${ }^{2}$ Bruno Goffé, ${ }^{2}$ \\ Kenneth A. Farley, ${ }^{1}$ and Yue-Gau Chen ${ }^{4}$ \\ Received 30 October 2006; revised 18 June 2007; accepted 6 July 2007; published 28 November 2007.
}

[1] The Taiwan mountain belt is classically viewed as a case example of a critical wedge growing essentially by frontal accretion and therefore submitted to distributed shortening. However, a number of observations call for a significant contribution of underplating to the growth of the orogenic wedge. We propose here a new thermokinematic model of the Taiwan mountain belt reconciling existing kinematic, thermometric and thermochronological constraints. In this model, shortening across the orogen is absorbed by slip on the most frontal faults of the foothills. Crustal thickening and exhumation are sustained by underplating beneath the easternmost portion of the wedge (Tananao Complex, TC), where the uplift rate is estimated to $\sim 6.3 \mathrm{~mm} \mathrm{a}^{-1}$, and beneath the westernmost internal region of the orogen (Hsueshan Range units, HR), where the uplift rate is estimated to $\sim 4.2 \mathrm{~mm} \mathrm{a}^{-1}$. Our model suggests that the TC units experienced a synchronous evolution along strike despite the southward propagation of the collision. It also indicates that they have reached a steady state in terms of cooling ages but not in terms of peak metamorphic temperatures. Exhumation of the HR units increases northward but has not yet reached an exhumational steady state. Presently, frontal accretion accounts for less than $\sim 10 \%$ of the incoming flux of material into the orogen, although there is indication that it was contributing substantially more $(\sim 80 \%)$ before $4 \mathrm{Ma}$. The incoming flux of material accreted beneath the TC significantly increased 1.5 Ma ago. Our results also suggest that the flux of material accreted to the orogen corresponds to the top $\sim 7 \mathrm{~km}$ of the upper crust of the underthrust Chinese margin. This indicates that a significant amount $(\sim 76 \%)$ of the underthrust material has been subducted into the mantle, probably because of the increase in density associated with metamorphism. We also show that the density distribution resulting from metamorphism within the orogenic wedge explains well the topography and the gravity field. By combining available geological data on the thermal and kinematic evolution of the wedge, our study sheds new light onto mountain building processes in Taiwan and allows for reappraising the initial structural architecture of the passive margin.

Citation: Simoes, M., J. P. Avouac, O. Beyssac, B. Goffé, K. A. Farley, and Y.-G. Chen (2007), Mountain building in Taiwan: A thermokinematic model, J. Geophys. Res., 112, B11405, doi:10.1029/2006JB004824.

\section{Introduction}

[2] Taiwan results from the collision between the Chinese continental margin and the Luzon volcanic arc. The Longitudinal Valley (LV), to the east of the island, is the suture between the two plates and separates the Taiwan mountain belt, which refers to the accreted passive margin sequences to the west, from the deformed volcanic arc to the east

\footnotetext{
${ }^{1}$ Tectonics Observatory, California Institute of Technology, Pasadena, California, USA.

${ }^{2}$ Laboratoire de Géologie, Ecole Normale Superieure, Centre National de la Recherche Scientifique, Paris, France.

${ }^{3}$ Now at Institut de Physique du Globe, Université Paris 7, CNRS, Paris, France.

${ }^{4}$ Department of Geosciences, National Taiwan University, Taipei, Taiwan.

Copyright 2007 by the American Geophysical Union. 0148-0227/07/2006JB004824\$09.00
}

(Figure 1). The convergence rate across the plate boundary is estimated to be $\sim 90 \mathrm{~mm} \mathrm{a}^{-1}$ from the GPS-derived plate model REVEL [Sella et al., 2002]. Over the long term, $\sim 42 \mathrm{~mm} \mathrm{a}^{-1}$ of this convergence rate has been absorbed by crustal shortening west of the LV [Simoes and Avouac, 2006]. The present study aims at quantifying the kinematic and thermal evolution of the mountain belt that has resulted from this process. We do not discuss the $\sim 48 \mathrm{~mm} \mathrm{a}^{-1}$ left to be accommodated on the Philippe Sea Plate side, in particular across the LV Fault [Shyu et al., 2006a], the Coastal Range (CoR) or across active faults offshore eastern Taiwan [Malavieille et al., 2002].

[3] The collision initiated $\sim 6.5 \mathrm{Ma}$ ago in the north [e.g., Lin et al., 2003] and has since propagated southward because of the obliquity of the Chinese continental margin relative to the Luzon volcanic arc [Byrne and Liu, 2002; Simoes and Avouac, 2006; Suppe, 1981, 1984]. Consequently, Taiwan offers the unique opportunity to investigate 

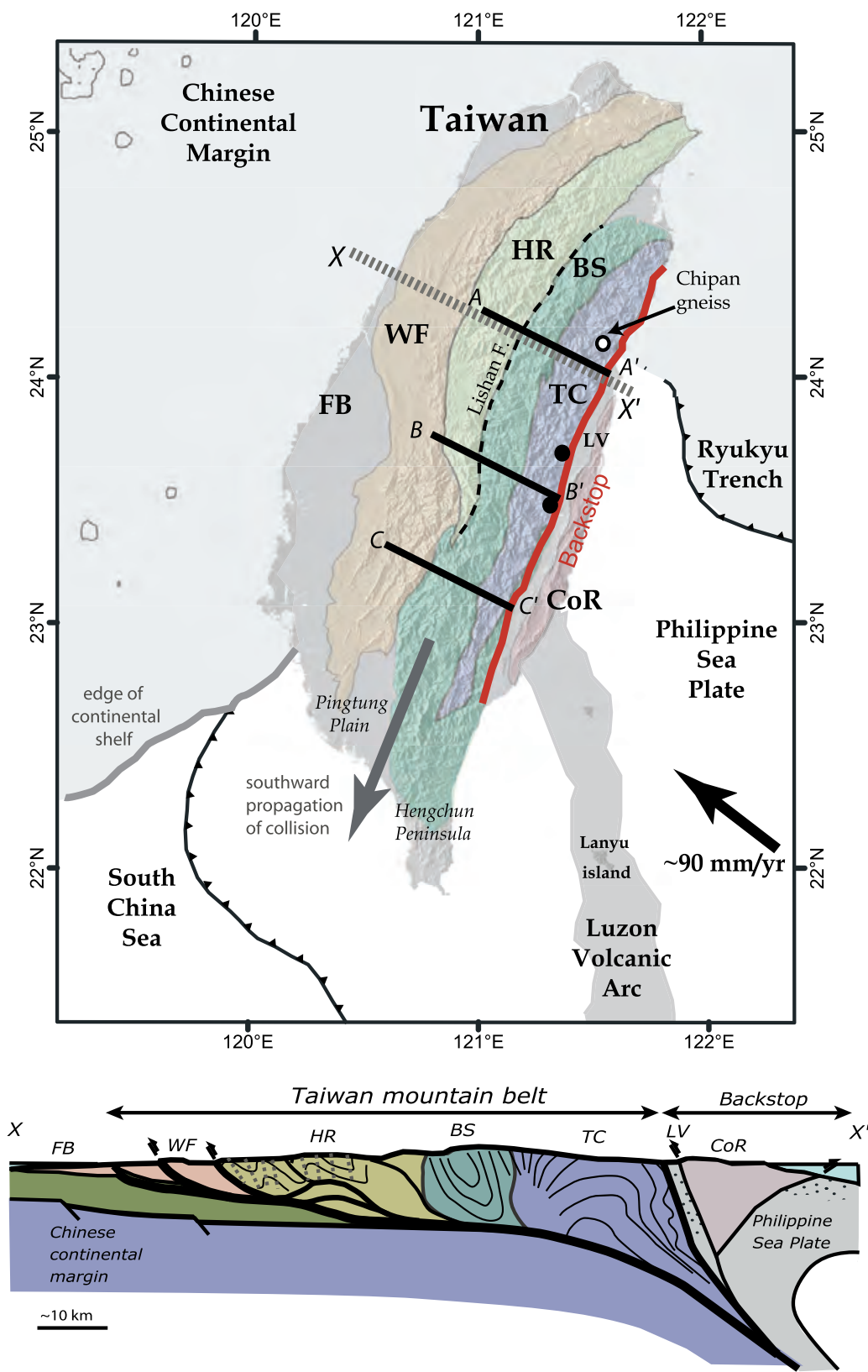

Figure 1. (top) Geodynamical and geological context of Taiwan. The suture zone between the Philippe Sea Plate and the Chinese passive margin lies along the Longitudinal Valley (LV) to the east of Taiwan. The Taiwan mountain belt refers to the orogenic belt that developed west of the LV and that involved accreted passive margin sequences. The $90 \mathrm{~mm} \mathrm{a}^{-1}$ convergence rate across the plate boundary is taken from the GPS-derived plate model REVEL [Sella et al., 2002]. Over the long-term a fraction of this convergence rate estimated to $\sim 42 \mathrm{~mm} \mathrm{a}^{-1}$ is absorbed across the Taiwan mountain belt [Simoes and Avouac, 2006]. The main tectonostratigraphic domains of the mountain belt are reported: from west to east, the foreland basin (FB), the Western Foothills (WF), the Hsueshan Range units (HR) separated from the Backbone Slates (BS) by the Lishan Fault (Lishan F), and the Tananao Complex (TC). To the east, the LV and the Coastal Range (CoR) are of Philippine Sea Plate affinity and are considered to form the backstop of the wedge. Three transects across the orogen $\left(\mathrm{AA}^{\prime}, \mathrm{BB}^{\prime}\right.$, and $\left.\mathrm{CC}^{\prime}\right)$ were investigated in this study and correspond to the three main roads crossing the mountain belt. Black dots report the location of two sites where exotic mafic bodies with high-pressure metamorphic mineralogy have been described [e.g., Beyssac et al., 2007]. (bottom) Cross section of line XX' (after Beyssac et al. [2007] and Malavieille and Trullenque [2007]). 
the temporal evolution of a young active mountain belt by comparing different transects across the orogen [e.g., Malavieille et al., 2002; Suppe, 1984]. Also, this mountain belt is relatively well documented in terms of structural geology [e.g., Clark et al., 1993; Crespi et al., 1996; Faure et al., 1991; Fisher et al., 2002; Ho, 1986, 1988; Pulver et al., 2002; Stanley et al., 1981; Suppe, 1981; Tillman and Byrne, 1995], metamorphism [e.g., Beyssac et al., 2007; Ernst, 1983; Ernst and Jahn, 1987], and thermochronology [e.g., Beyssac et al., 2007; Fuller et al., 2006; Liu et al., 2001; Lo and Onstott, 1995; Tsao, 1996; Willett et al., 2003] (Figures 1 and 2). Because of its exemplarity, Taiwan has proved to be a key natural laboratory for the development of the popular critical wedge model of mountain building, which holds that a range adjusts to erosion at the surface and to the flux of incoming material due to frontal accretion and/or basal underplating so as to maintain a stable selfsimilar geometry dictated by the internal friction angle of the medium and by the shear stresses at the base of the wedge [e.g., Chapple, 1978; Dahlen and Barr, 1989; Davis et al., 1983; Suppe, 1981]. Early models of the Taiwan mountain belt proposed that erosion of the orogenic wedge has been compensated essentially by frontal accretion of material, with less than $25 \%$ of underplating [Barr and Dahlen, 1989; Barr et al., 1991; Dahlen and Barr, 1989]. In this case, shortening is expected to be distributed throughout the whole mountain belt to maintain the stable geometry of the wedge [e.g., Avouac, 2003; Willett et al., 2001]. The view that this mountain belt has grown mainly by frontal accretion is challenged by recent data on the kinematics of shortening across the wedge. From the analysis of the foreland basin and of the thrust sheets accreted to the foothills, Simoes and Avouac [2006] have shown that the $\sim 42 \mathrm{~mm} \mathrm{a}^{-1}$ shortening rate across the mountain belt are taken up mostly (if not only) by slip on the thrust faults of the foothills, rather than being distributed throughout the whole orogen. This observed kinematics therefore indicates that orogenic growth and erosion at the surface are sustained by underplating rather than by frontal accretion. Previous investigations have also emphasized the possible importance of underplating in Taiwan, based on structural arguments [Hwang and Wang, 1993], strain magnitudes determined from mineral pressure shadows [Clark et al., 1993] or low-temperature thermochronological data [Fuller et al., 2006]. In addition, a wealth of data on peak metamorphic temperatures and (U-Th)/He lowtemperature thermochronology has been recently produced on several transects across the Taiwan mountain belt [Beyssac et al., 2007] and appears inconsistent with the thermal evolution predicted by the initial models of Barr and Dahlen [1989], Dahlen and Barr [1989], and Barr et al. [1991] (Figure 2). In particular, these models as well as the more recent doubly vergent wedge model of Fuller et al. [2006] are not able to reproduce with realistic kinematics the high peak metamorphic temperatures observed to the east (Tananao Complex, TC), as well as the large exhumation of the westernmost portion of the Taiwan mountain belt (Hsueshan Range units, HR), suggesting that either these models need refinement or observed peak metamorphic temperatures were attained prior to the MioPliocene orogeny. The purpose of this study is to quantitatively reappraise the thermokinematic evolution of the
Taiwan mountain belt by integrating and reconciling these recent findings and data. In our analysis, we follow the forward modeling approach of Henry et al. [1997] and Bollinger et al. [2006]. The kinematics is prescribed and we then solve for the temporal evolution of the thermal structure. This makes it possible to compute P-T-t paths and adjust the model to thermometric and thermochronological data. We present here a plausible kinematic scenario constrained by available data on the thermal and metamorphic evolution of the Taiwan mountain belt, and consistent with the structural architecture of the wedge.

\section{Structural Framework and Constraints on the Thermokinematic Evolution of the Mountain Belt}

\subsection{Stratigraphic and Structural Background}

[4] The Taiwan mountain belt originated from the collision between the Luzon volcanic arc and the Chinese passive margin and develops west of the LV (Figure 1). The most internal and metamorphosed portion of the wedge is exposed within the Tananao Complex (TC) and is composed of highly deformed pre-Tertiary basement. Kinematic indicators of left-lateral shear have been found in the eastern TC units along the LV, and are related to the slight obliquity $\left(\sim 10^{\circ}\right)$ between the direction of transport and the structural trend in Taiwan [e.g., Faure et al., 1991; Pulver et al., 2002]. The TC is stratigraphically overlain by metasediments of the slate belt, originally deposited in the passive margin during rifting and opening of the South China Sea [e.g., Ho, 1986, 1988]. The slate belt is constituted of the Eocene and Miocene metasediments of the Backbone Slates (BS) and of the Eocene to Oligocene metasediments of the Hsueshan Range units (HR). These two ensembles are separated by the Lishan Fault (LF) (Figure 1). We use the terminology "Backbone" for consistency with some earlier tectonostratigraphic classifications, in particular that of Ho [1988]. Hereafter BS and HR refer to these two different tectonostratigraphic provinces of the slate belt.

[5] An overall top-to-the-west sense of shear is observed in the TC and eastern BS [Clark et al., 1993; Faure et al., 1991; Fisher et al., 2002; Tillman and Byrne, 1995]. The HR only outcrops over the northern half of the Taiwan mountain belt and vanishes to the south where the orogen is younger (Figure 1). The general structure of the HR suggests that it is related to some duplex system along the main decollement [Powell, 2003]. Well-documented coaxial deformation within the HR [Clark et al., 1993; Tillman and Byrne, 1995] suggests in addition that some shortening must have been absorbed by penetrative deformation. West of these internal units of the Taiwan mountain belt, the foldand-thrust-belt of the Western Foothills (WF) consists of nonmetamorphic synorogenic sediments initially deposited in the adjacent foreland basin of Taiwan. To the south, the easternmost part of the WF shows complex duplex systems [e.g., Hickman et al., 2002; Hung et al., 1999; Mouthereau et al., 2001; Suppe, 1980; Yang, 2007], and it has been proposed that these structures are younger structural equivalents of the structures observed in the Hsueshan Range to the north [Simoes and Avouac, 2006]. The thrust faults of the WF root into a common decollement at a depth of about $\sim 5 \mathrm{~km}$ [e.g., Yue et al., 2005]. It has been suggested that 

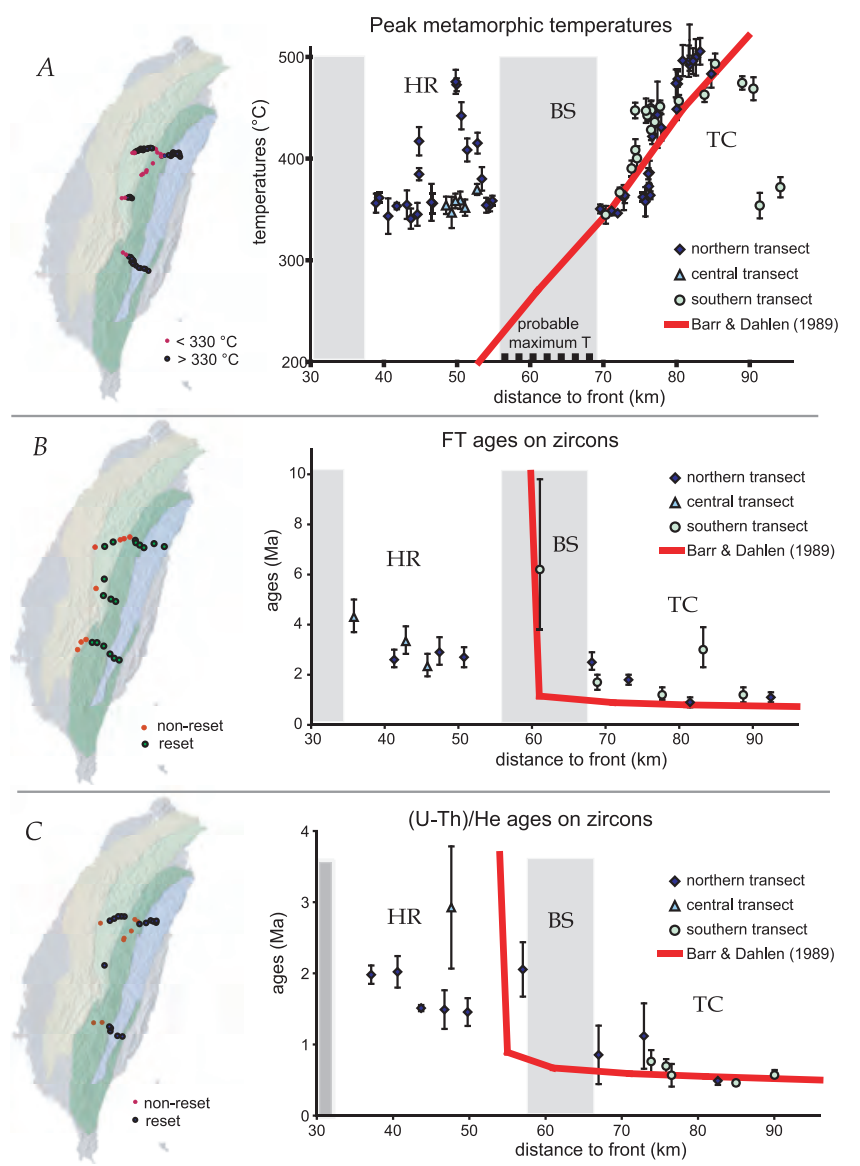

Figure 2. Thermometric and thermochronologic data along the three transects presented in Figure 1. These data are compared to the predictions of the thermokinematic model of Dahlen and Barr [1989], Barr and Dahlen [1989], and Barr et al. [1991] for 25\% of underplating below the orogen (red line). Note that the vertical scale is different for FT and (U-Th)/He ages. Maps locate samples for the different data sets. (a) Peak metamorphic temperatures retrieved from RSCM thermometry [Beyssac et al., 2007]. The location of data below the $330^{\circ} \mathrm{C}$ resolution limit [Beyssac et al., 2002] is indicated by the shaded areas on the graph and by red dots on the map. A maximum peak temperature of $200^{\circ} \mathrm{C}$ is proposed for most of the BS because FT and (U-Th)/He ages on zircon are not reset in this area (Figures $2 \mathrm{~b}$ and 2c). (b) FT $\chi^{2}$ ages on detrital zircons from Liu et al. [2001]. Data from Tsao [1996] are not shown here since they are consistent with those of Liu et al. [2001]. Shaded areas on the graph and red dots on the map locate where FT ages on zircon are not reset. A closure temperature of $240^{\circ} \mathrm{C}$ was considered for model predictions (red line). (c) (U-Th)/He ages on detrital zircons [Beyssac et al., 2007]. Shaded areas on the graph and red dots on the map locate where these ages are not reset. A closure temperature of $180^{\circ} \mathrm{C}$ has been assumed to estimate the ages predicted from the model (red line).

this decollement can be traced in the background microseismicity as a continuous feature extending beneath the whole mountain belt with a $\sim 9-10^{\circ}$ east dip angle [Carena et al., 2002], although this pattern is not that prominent in most recent catalogues of relocated seismicity [Wu et al., 2007]. In addition, by balancing incoming and outcoming fluxes of material across the wedge, Simoes and Avouac [2006] found that the decollement beneath the orogen needs to be slightly steeper $\left(\sim 17^{\circ} \mathrm{E}\right)$, to reach deep enough so that the mountain belt in northern Taiwan is approximately in steady state as suggested by its constant width. The geometry and nature of the contact between the mountain belt and the LV is poorly constrained by geophysics [e.g., Kim et al., 2005; McIntosh et al., 2005]. Recent data on three-dimensional (3-D) high-resolution $\mathrm{V}_{\mathrm{p}}$ and $\mathrm{V}_{\mathrm{s}}$ tomography [Wu et al., 2007] indicate that this contact is probably quite steep $\left(\sim 70-80^{\circ}\right)$ but do not allow for clearly discriminating between an east or west dipping geometry.

\subsection{Constraints on the Thermal and Metamorphic Evolution of the Taiwan Mountain Belt}

[6] We provide here an overview of available petrologic and thermochronologic data, which are discussed in more details by Beyssac et al. [2007]. Except for some exotic mafic bodies located along the suture zone (Figure 1), which yield $\sim 8-14$ Ma blueschist metamorphic conditions ( $\left.\sim 450-500^{\circ} \mathrm{C},>7 \mathrm{kbar}\right)$ [Ernst and Jahn, 1987; Liou et al., 1975; Lo and Yui, 1996], petrologic constraints are rather scarce throughout the Taiwan mountain belt because of the poorly developed mineralogy. However, peak metamorphic temperatures have been recently documented from the Raman spectroscopy of carbonaceous material (RSCM thermometry) within the slate belt and eastern TC [Beyssac et al., 2007] (Figure 2). The cooling history of rocks up to the surface is constrained by thermochronology. The ${ }^{40} \mathrm{Ar}-{ }^{39} \mathrm{Ar}$ ages on hornblende, muscovite, and biotite for the Chipan gneiss [Lo and Onstott, 1995] and K-Ar data on white mica fine $(<2 \mu \mathrm{m})$ fractions [Tsao, 1996] along the main transects across the mountain belt (Figure 1) document the higher temperature history. An extensive data set of fission track (FT) [Liu et al., 2001; Tsao, 1996] and (U-Th)/ $\mathrm{He}$ [Beyssac et al., 2007] ages on detrital zircons is also available (Figure 2). There are also some (U-Th)/He [Beyssac et al., 2007] and FT [Fuller et al., 2006; Willett et al., 2003] ages on apatites, but we do not specifically refer to them in this analysis because of their high sensitivity to surface conditions (in particular to local relief evolution) rather than to the presumably more stable processes at depth. Altogether, these data show consistent patterns across the orogen: RSCM temperatures do not exceed the $330^{\circ} \mathrm{C}$ lower limit of the technique [Beyssac et al., 2002] within most of the BS and within the WF where thermochronological ages are nonreset. RSCM temperatures are as high as $\sim 500^{\circ} \mathrm{C}$ and $\sim 475^{\circ} \mathrm{C}$ in the TC and in the core of the HR, respectively, where all low-temperature cooling ages are fully reset and young (Figure 2). Peak metamorphic temperatures determined for the slate belt undoubtedly represent the thermal conditions within the basins of the passive margin or during the ongoing orogeny in Taiwan because these metasediments have not undergone any other thermal event. The basement rocks of the TC have a polymetamorphic history and the timing of the RSCM temperatures obtained in these units is uncertain. Lo and Onstott [1995] report a fully reset ${ }^{40} \mathrm{Ar}-{ }^{39} \mathrm{Ar}$ age on biotite of $7.7 \mathrm{Ma}$ for the Chipan gneiss. The ${ }^{40} \mathrm{Ar}^{-39} \mathrm{Ar}$ ages on coarse hornblendes and muscovites are only partially reset because of the 

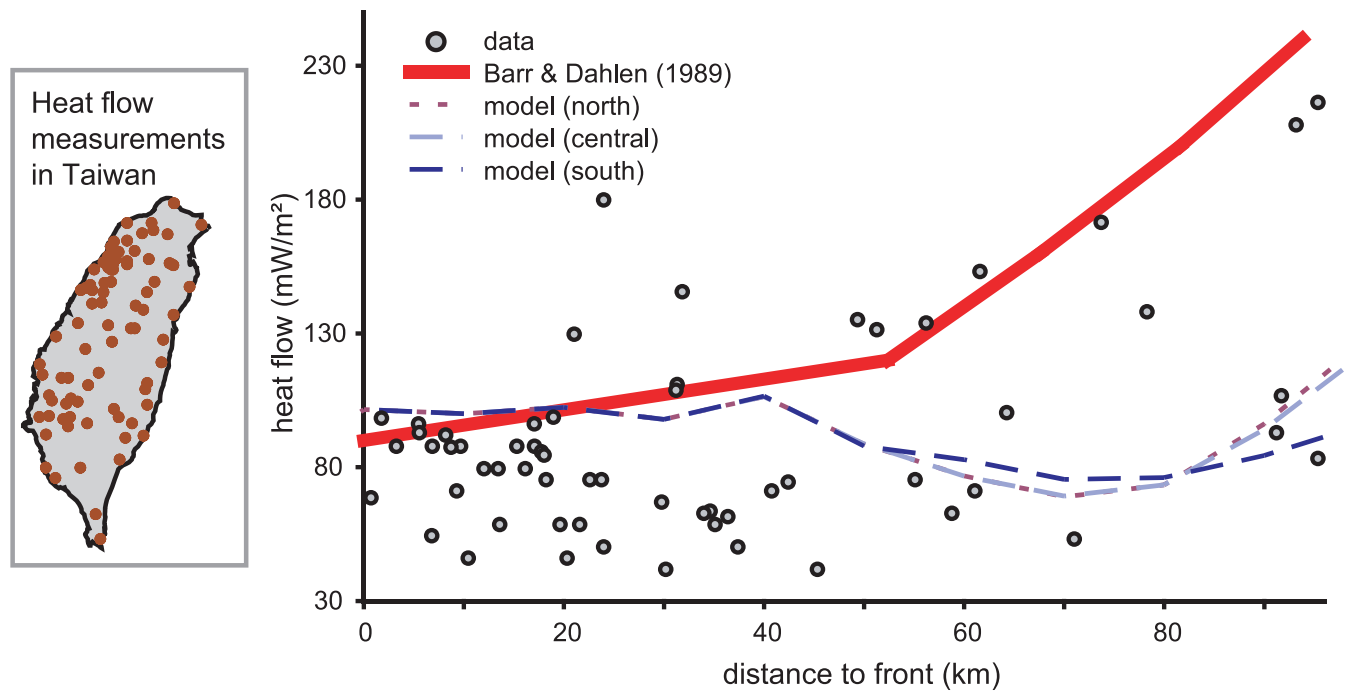

Figure 3. Heat flow measurements [Lee and Cheng, 1986] and predictions from our model (dashed lines) and from the model of Barr and Dahlen [1989] and of Barr et al. [1991] that assume 25\% of underplating (red line). When plotted along a transect across the Taiwan mountain belt, heat flow data show a significant scatter that does not allow for clearly testing thermal models. Left inset shows location of measurements over Taiwan.

presence of second generation fine grained actinolitic amphiboles and phengites. Lo and Onstott [1995] propose that the ${ }^{40} \mathrm{Ar}^{39} \mathrm{Ar}$ ages of these second-generation minerals are of 7.8 and $6.4 \mathrm{Ma}$ on amphiboles and phengites, respectively, based on the Ar isotopic composition of the actinolitic reaction rim of amphiboles and on the abundance of phengite flakes with respect to coarse muscovites. Lo and Onstott [1995] quantitatively argue that coarse muscovites and hornblendes may not have been fully reset because of the short duration of the thermal overprinting (probably less than 3 to $4 \mathrm{Ma}$ ). They use for that the thermal model of Barr and Dahlen [1989], which predicts peak metamorphic temperatures consistent with RSCM data (Figure 2). It is therefore highly probable that the core of the TC was subjected to temperatures as high as $\sim 450$ to $500^{\circ} \mathrm{C}$ during the ongoing Taiwan orogeny, such that the high RSCM temperatures obtained in the basement units are representative of the current orogenic phase, as further discussed by Beyssac et al. [2007]. Altogether these data indicate that exhumation has reached to quite deep levels in the $\mathrm{TC}$ and HR, but that it has been minor for most of the BS (Figure 2). In addition, the RSCM temperatures and thermochronological ages indicate a northward increase in exhumation for the HR, from the southern to the northern transects (Figure 2). In contrast, these data do not show any major along-strike variations within the TC, suggesting that this unit has probably reached a thermal and exhumational steady state as defined by Willett and Brandon [2002] or that it had a laterally synchronous evolution (see discussion by Beyssac et al. [2007]).

[7] Some caution must be taken regarding the choice of closure temperatures used in modeling thermochronological data. Here we assume a closure temperature of $230-260^{\circ} \mathrm{C}$ for the FT ages on zircon [Liu, 1982; Liu et al., 2001]. In the case of (U-Th)/He ages on zircon, a closure temperature of $180^{\circ} \mathrm{C}$ is usually assumed [e.g., Reiners et al., 2004], but we subsequently consider possible values of 150 to $180^{\circ} \mathrm{C}$ to account for the relative small size of the minerals and for the rapid exhumation rates [Beyssac et al., 2007]. Because of the small size of the white micas dated by K-Ar by Tsao [1996], the significance of these ages in terms of a simple closure temperature is uncertain. In Figure 2, we report the predictions of the thermokinematic model of Dahlen and Barr [1989], Barr and Dahlen [1989], and Barr et al. [1991] in terms of peak metamorphic temperatures and of the various low-temperature cooling ages. This model predicts reasonably well the data over the easternmost BS and over the TC provided that some underplating is allowed at depth (here $25 \%$ of incoming flux of material). It should be noted though that these authors assumed a total shortening rate of $70 \mathrm{~mm} \mathrm{a}^{-1}$ across the Taiwan mountain belt, a value too high in light of the $42 \mathrm{~mm} \mathrm{a}^{-1}$ recently estimated by Simoes and Avouac [2006]. In any case, this model, as well as the more recent thermomechanical model of Fuller et al. [2006], fails to reproduce the amount and rate of exhumation of the HR as observed from the various data.

[8] Some surface heat flow data are also available [Lee and Cheng, 1986] (Figure 3) and can be used in principle to test thermokinematic models. The reliability of most of these measurements is questionable because some of the boreholes are only 100 to $200 \mathrm{~m}$ deep and thus potentially affected by the effects of temperature changes at the surface. Also, some extremely low $\left(<30 \mathrm{~mW} \mathrm{~m}^{-2}\right)$ and high values $\left(>250 \mathrm{~mW} \mathrm{~m}^{-2}\right)$ probably correspond to areas perturbed by hydrothermal activity and by groundwater circulation [Song and $M a, 2002]$. In any case, these data show a considerable scatter (Figure 3), so that they do not provide a tight constraint on our model.

\subsection{Kinematics}

[9] Because of their geologic affinity with the Philippine Sea plate $[H o, 1986]$ and because crustal thickening is limited in this area [Hetland and Wu, 1998; Shih et al., 1998; Yeh et al., 1998], the LV and the CoR are considered 


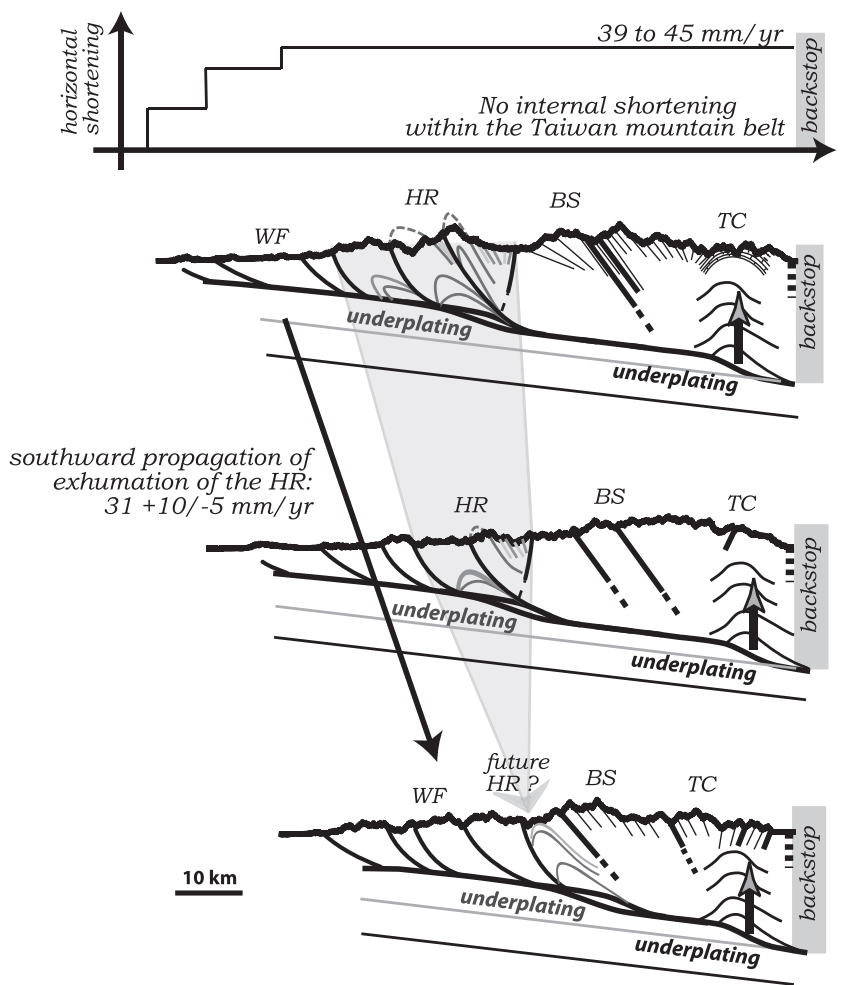

Figure 4. Tectonic evolution of the Taiwan mountain belt as modeled in this study. The cross sections along the three transects shown in Figure 1 are expected to represent different temporal stages of the evolution of the orogenic wedge. Note the progressive exhumation of the HR units, with a southward propagation rate of $31+10 /-5 \mathrm{~mm} \mathrm{a}^{-1}$ [Simoes and Avouac, 2006]. Horizontal shortening across the wedge is accommodated by slip on the most frontal faults of the foothills [Simoes and Avouac, 2006; Simoes et al., 2007a, 2007b]. The range grows essentially by underplating below the $\mathrm{HR}$ and the TC [Beyssac et al., 2007] (Figure 2). See text for further details.

to form the backstop of the Taiwan mountain belt [e.g., Simoes and Avouac, 2006] (Figure 1). The portion of the convergence rate between the two plates that is solely absorbed as shortening across the mountain belt has been recently estimated to be $39-45 \mathrm{~mm} \mathrm{a}^{-1}$ (over the last $2 \mathrm{Ma}$ ), and it appears to have been mostly accommodated by slip on the frontal thrust faults of the WF [Simoes and Avouac, 2006] (Figure 4). Shortening within the internal portions of the mountain belt is therefore negligible and cannot account for the observed exhumation and wedge thickening. This kinematics requires that exhumation and erosion at the surface are sustained by underplating rather than by frontal accretion. In particular, thermometric and thermochronological constraints indicate that underplating is most probably localized beneath the TC and the HR [Beyssac et al., 2007] (Figures 2 and 4). We view underplating as resulting from the discrete accretion of thrust sheets with the development of duplexes as observed in exhumed mountain ranges [Dunlap et al., 1997] or in analogue experiments [Konstantinovskaia and Malavieille, 2005]. The details of the subsurface geometry and structural evolution of the orogen are not known, so that rather than modeling the discrete evolution of poorly constrained duplex systems, we assume here a continuous process of underplating, as done in previous similar modeling studies [e.g., Barr and Dahlen, 1989; Bollinger et al., 2006; Fuller et al., 2006].

[10] Because of the southward propagation of the collision related to the obliquity between the Chinese passive margin and the Luzon volcanic arc, transects at different latitudes across the Taiwan mountain belt are expected to correspond to different temporal stages of evolution of the wedge. The sedimentation history in the foreland basin suggests that the flexural response of the basin to the growth of the mountain belt has migrated southward at a rate of $31+10 /-5 \mathrm{~mm} \mathrm{a}^{-1}$ [Simoes and Avouac, 2006]. This rate differs somewhat from the 55 to $90 \mathrm{~mm} \mathrm{a}^{-1}$ propagation rate previously estimated from geometric considerations [Byrne and Liu, 2002; Suppe, 1981, 1984] and may reflect the fact that the underthrust passive margin did not have a NE-SW geometry similar to that presently observed south of Taiwan. The southward development of the foreland basin correlates specifically with the lateral growth of the Hsueshan Range, which constitutes the major frontal topography loading the foreland. The rate of $31+10 /-5 \mathrm{~mm} \mathrm{a}^{-1}$ can therefore be used to translate the different transects across the HR into temporal stages but may not apply to other structures. Figure 4 shows schematically the structural evolution of the Taiwan mountain belt, which is the basis of our thermokinematic modeling. The three well-documented transects across the wedge (Figure 1) are represented. Note that we do not attempt to account for the orogen north of the central cross-island highway $\left(\mathrm{A}-\mathrm{A}^{\prime}\right.$ transect in Figure 1), since the reversal of the subduction polarity at the Ryukyu Trench [e.g., Suppe, 1984] and back-arc extension probably affect crustal deformation in this region.

[11] The kinematics of mountain building determines the overall stratigraphic and structural architecture of a mountain belt. In Figure 5, we depict two simple kinematic models, in which internal shortening of the wedge is assumed negligible. These models differ only in the assumed direction of overthrusting. The stratigraphic sequence is expected to be normal if overthrusting and underthrusting are in the same direction, and to be overturned in the opposite case. Here overturning is produced by velocity gradients across the accretion windows and not by gradients within the wedge. These sketches assume continuous accretion. In reality, accretion is probably a discontinuous process resulting from discrete episodes of formation of thrust sheets. In this case, the individual accreted units may keep a normal polarity. The overall overturning depicted in Figure 5 might then only hold at a regional scale, and in the case that this kinematics has been sustained for a period of time long enough to have exhumed units accreted at depth. Figure 5 also illustrates how the sense of overthrusting relates to the geometry of the contact between the wedge and its backstop.

\section{Modeling Setup}

\subsection{Modeling Approach}

[12] We use the 2-D finite element code FEAP, developed by R. Taylor (University of California, Berkeley), and modified by P. Henry (CNRS, France) [Henry et al., 1997]. This code allows for solving the transient thermal evolution of the orogen and integrates erosion. It is appropriate to 


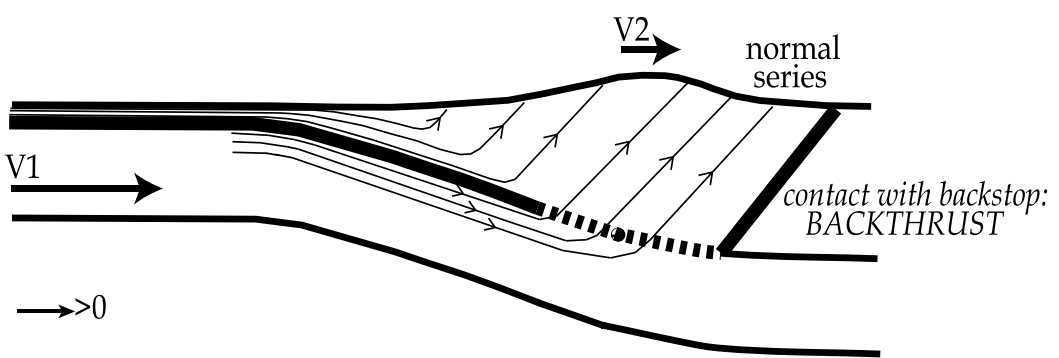

$\mathrm{V} 1-\mathrm{V} 2$ = total shortening rate across the wedge

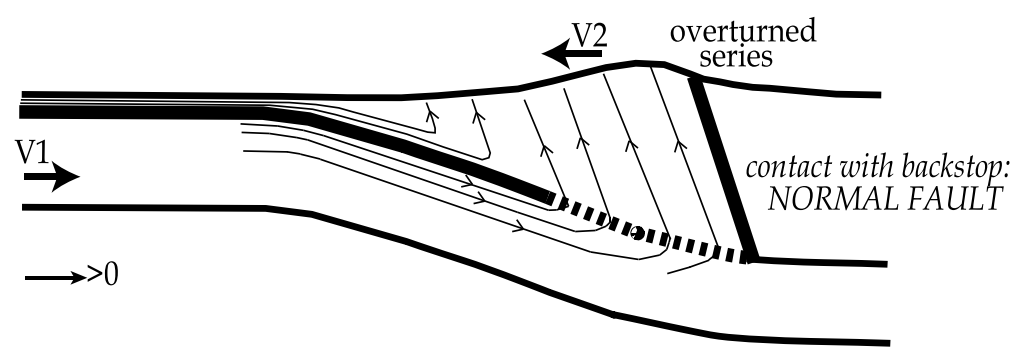

Figure 5. Influence of the overthrusting direction on the overall structure of an orogenic wedge. $V_{1}$ and $V_{2}$ correspond to the underthrusting and overthrusting velocities, respectively, relative to the basal decollement. They are taken positive in the sense of the lower plate motion. The two sketches assume negligible internal shortening of the orogenic wedge. (top) Positive $V_{2}$, such as in doubly vergent orogen models [e.g., Willett et al., 1993]. In this case the normal polarity of the stratigraphic sequences accreted to the orogen is preserved, and the contact with the backstop is a kinematic back thrust. (bottom) Negative $V_{2}$. The accreted stratigraphic sequence is overturned, and the contact with the backstop is a kinematic normal fault. In these sketches the accretion of discrete thrust sheets is approximated by a continuous process. This approximation only holds at a regional scale and if underplating has been going on for a certain time.

implement the kinematics proposed for the Taiwan mountain belt, with underplating and no shortening accommodated within the orogenic wedge. Heat equations are solved within an Eulerian frame [Zienkiewicz and Taylor, 1989] and account for diffusion, advection and internal heat sources such as radiogenic heat production and shear heating. Shear heating is computed from the thickness and the velocity discontinuity across the shear zone, as well as from the shear stress. The shear stress depends on the assumed friction coefficient, as well as on the lithostatic pressure calculated from the petrogenetic grid of Bousquet et al. [1997] (see Henry et al. [1997] for more details on this computation). In order to account for shear heating in the ductile regime, stresses are estimated in this case from a nonlinear flow law that depends on the strain rate and on the material properties. Parameters used to compute lithostatic pressures and shear heating are summarized in Tables 1 and 2 . The code allows for the computation of peak temperatures and cooling ages by particle tracking through the timedependent thermal field [Bollinger et al., 2006].

[13] The details of the kinematics and thermal structure of the WF are ignored because they do not affect the thermal structure of the more internal portions of the wedge. The kinematic scheme of the model is illustrated in Figure 6.

Table 1. Thermal and Physical Parameters Used in Our Thermokinematic Modeling ${ }^{\mathrm{a}}$

\begin{tabular}{|c|c|c|c|c|c|c|c|}
\hline \multirow[b]{2}{*}{ Parameter } & \multicolumn{7}{|c|}{ Layer } \\
\hline & LPM & LPLC & LPUC & $\begin{array}{l}\text { Shear } \\
\text { Zone }\end{array}$ & $\mathrm{OP}$ & UPC & UPM \\
\hline Conductivity, $\mathrm{W} \mathrm{m}{ }^{-1} \mathrm{~K}^{-1}$ & 2.9 & 2.9 & 3.35 & 3.35 & 3.35 & 2.9 & 2.9 \\
\hline Thermal diffusivity, $\mathrm{m}^{2} \mathrm{~s}^{-1}$ & $10^{-6}$ & $10^{-6}$ & $10^{-6}$ & $10^{-6}$ & $10^{-6}$ & $10^{-6}$ & $10^{-6}$ \\
\hline Radioactivity, $\mu \mathrm{W} \mathrm{m}^{-3}$ & 0 & 0.39 & 1.7 & 1.7 & 1.7 & 0 & 0 \\
\hline Chemical composition & Per & Inter & Granod & Granod & Granod & gabbro & Per \\
\hline Density & 3.35 & 2.91 & 2.76 & 2.76 & 2.76 & 2.94 & 3.35 \\
\hline Thermal expansion, $\mathrm{K}^{-1}$ & $2.4 \mathrm{E}-05^{\mathrm{b}}$ & $2.4 \mathrm{E}-05$ & $2.4 \mathrm{E}-05$ & $2.4 \mathrm{E}-05$ & $2.4 \mathrm{E}-05$ & $2.4 \mathrm{E}-05$ & $2.4 \mathrm{E}-05$ \\
\hline Compressibility, $\mathrm{Pa}^{-1}$ & $8 \mathrm{E}-12$ & $1 \mathrm{E}-11$ & 2E-11 & 2E-11 & 2E-11 & $1 \mathrm{E}-11$ & $8 \mathrm{E}-12$ \\
\hline
\end{tabular}

${ }^{\mathrm{a}}$ The different layers refer to those represented in Figure 7. Conductivity and radioactivity for the LPUC, the shear zone, and the OP were taken from Lee and Cheng [1986], Chang [1989], and Song and Ma [2002], respectively. Radioactive heat production for the LPLC is from Zhou et al. [2003]. Densities are given for each rock chemical composition based on the computations of Bousquet et al. [1997] for surface conditions. These compositions are peridotite (Per), intermediate (Inter), granodiorite (Granod), and gabbro. The evolution of densities for metasediments and granodioritic compositions are similar at the PT conditions modeled in this study. The thermal expansion coefficient is after Taylor and McLennan [1985], and the compressibility is after Turcotte and Schubert [2002]. Thermal expansion and material compressibility were used to recalculate densities and lithostatic pressure with the procedures described by Bousquet et al. [1997] and Henry et al. [1997].

${ }^{\mathrm{b}}$ Read $2.4 \mathrm{E}-05$ as $2.4 \times 10^{-5}$. 
Table 2. Parameters Used to Compute Shear Heating, Using a Granite Rheology ${ }^{\mathrm{a}}$

\begin{tabular}{ll}
\hline \multicolumn{1}{c}{ Parameter } & \multicolumn{1}{c}{ Value } \\
\hline Brittle mode & \\
$\tau$ max, $\mathrm{MPa}$ & 50 \\
Effective friction & 0.1 \\
& \\
Ductile mode & $2.512 \times 10^{9}$ \\
$\mathrm{~A}, \mathrm{MPa}^{-\mathrm{n}} \mathrm{s}^{-1}$ & 3.4 \\
$\mathrm{n}$ & 139 \\
$\mathrm{Q}, \mathrm{kJ} \mathrm{mol}^{-1}$ & \\
\hline
\end{tabular}

${ }^{\mathrm{a}}$ Flow law parameters are after Hansen and Carter [1982].

The topography is assumed steady state. As in the configuration of Huerta et al. [1998], the reference frame is attached to the basal shear zone, and the model origin is taken at the intersection of this shear zone with the topographic surface. Velocities are taken positive from west to east in the sense of underthrusting, and upward for the verticals. Dip angles are positive when dipping to the east. The horizontal components of the underthrusting and overthrusting velocities, $V_{1}$ and $V_{2}$, respectively, are constant within the footwall and hanging wall, and $V_{1}-V_{2}$ is the total shortening rate across the mountain belt (Figure 6). Underplating and frontal accretion are modeled as continuous processes by allowing material transfer through the basal shear zone, across an underplating window where rocks would presumably undergo noncoaxial deformation (top-tothe-west shear in this case) (Figure 6). To satisfy the continuity equation, vertical shear within the hanging wall is allowed. The model therefore assumes vertical hinge lines, which meet the decollement at the updip and downdip limits of the underplating windows or at discontinuities on the decollement dip angle (Figure 6). We assume here that the footwall does not deform below the decollement so that the underplating rate $V_{u}$ is uniquely determined from the decollement geometry and the underthrusting velocity vector. Along the underplating windows, the horizontal footwall velocity vector $V_{1}$ partitions into the underthrusting velocity parallel to the footwall and into a vertical underplating vector $V_{u}$ transmitted to the hanging wall. If $\alpha$ is the dip angle of the basal thrust at this level and $\delta$ is the dip angle of the underthrusting velocity, then $V_{u}=V_{1} \tan (\alpha-\delta)$. Frontal accretion is modeled from an underplating window that reaches the surface. Overthrusting of the hanging wall over the shear zone with a horizontal velocity $V_{2}$ implies a vertical component in the particle trajectories of $-V_{2} \tan (\alpha)$. Rock uplift $U$ above the underplating window equals $V_{1}$ $\tan (\alpha-\delta)-V_{2} \tan (\alpha)$. Since we assume steady state topography, the model implicitly assumes an erosion rate $e$ that depends on rock uplift $U$ and on the topographic slope $\beta$ (inset in Figure 6).

\subsection{Model Geometry and Parameters}

[14] Six domains of uniform thermal and physical properties (Tables 1 and 2 and Figure 7) are considered: (1) the mantle, (2) lower crust and (3) upper crust of the underthrusting plate; (4) the orogenic wedge; and (5) the mantle and (6) oceanic crust of Pacific plate affinity, which represent the backstop of the mountain belt to the east. The mesh of our finite element model is $10 \mathrm{~km} \times 1.5 \mathrm{~km}$ within the wedge. We assume that the lithosphere of the downgoing plate is $80 \mathrm{~km}$ thick, based on the stretching factor of 1.5 related to extension and opening of the South China Sea [Lin et al., 2003]. The Moho has a depth of $30 \mathrm{~km}$ in the undeformed continental margin and dips $\sim 11.5^{\circ}$ to the east beneath the orogen, as estimated from geophysics [Kim et al., 2005; Lin, 2005; Shih et al., 1998; Yeh et al., 1998; Yen et al., 1998]. The base of the upper crust of the lower plate is set to $20 \mathrm{~km}$ [Shih et al., 1998]. As for the backstop, a $20 \mathrm{~km}$ thick oceanic crust [Hetland and Wu, 1998; Yeh et al., 1998] is considered. The geometry of the shear zone at the base of the wedge and the geometry of the contact between the wedge and the backstop are poorly constrained and are therefore adjusted by error and trial to fit the available constraints. A thickness of $1 \mathrm{~km}$ is attributed to this contact (Figure 7). The width (horizontal extent) and location of the underplating windows, and the underplated flux beneath the HR and TC are also adjusted by trial and error.

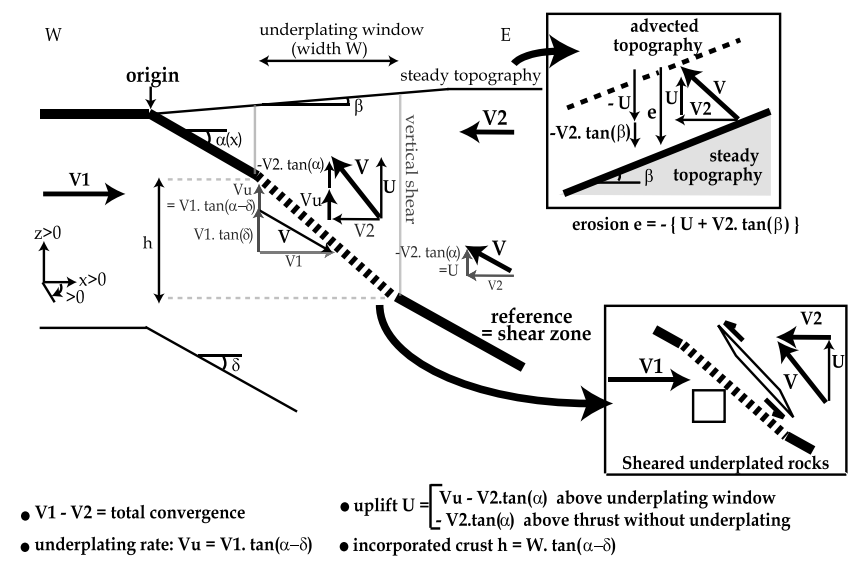

Figure 6. Geometry and kinematics in our thermokinematic finite element model. The basal shear zone of the orogen is taken as the reference for the velocity field. The topography is assumed steady state (constant in this reference frame). The divergence of the velocity field is zero to insure mass conservation. Deformation of the wedge, required to accommodate lateral variations of the underplating rate, is restricted to hinge lines assumed vertical (vertical gray lines). For simplicity, the footwall is assumed undeformed once it has passed through the hinge line at $x=0$. This is not necessarily true in reality but a reasonable assumption given that the data analyzed here are not sensitive to any eventual footwall deformation. Where the shear zone and the Moho are parallel $(\alpha=\delta)$, underplating is not allowed. The thickness $h$ of the crust incorporated into the orogen may be easily calculated from the dip angles $\alpha$ and $\delta$ of the shear zone and of the underthrusting velocity, as well as from the width $W$ of the underplating window. Since topography is assumed to be steady state, modeled erosion $e$ has to balance the total rock uplift $U$ as well as the lateral advection $V_{2}$ of the topography (top inset). Given the velocity field, underplated units are deformed and sheared across the basal decollement, and the shear direction is parallel to the decollement. This is illustrated in the bottom inset by the deformed geometry acquired across the underplating window of an initially square volume. See text for further details. 

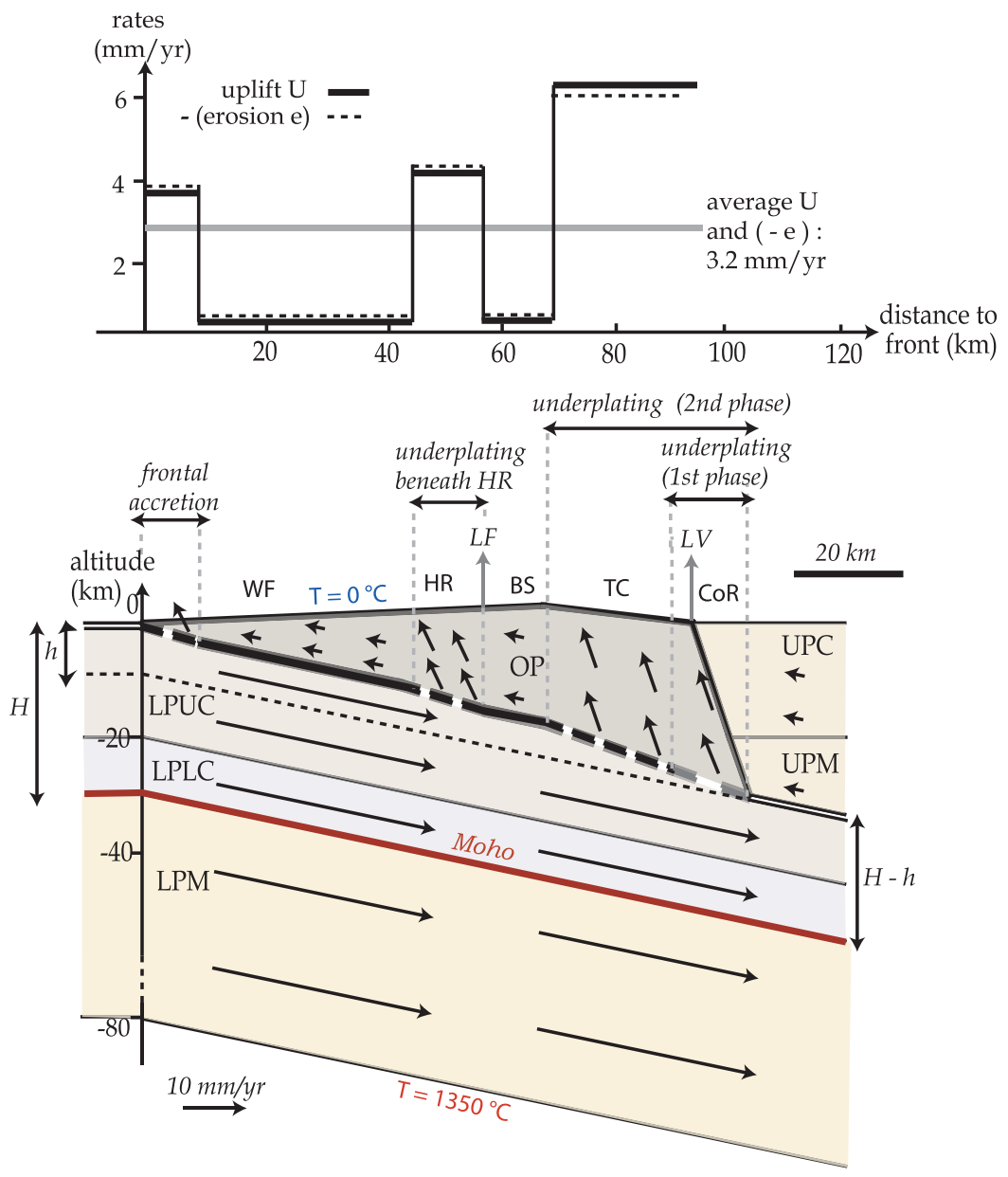

Figure 7. (bottom) Geometry of our preferred thermokinematic model, with the different domains of homogeneous thermal and kinematic properties (Table 1): lower plate mantle (LPM), lower plate lower crust (LPLC), lower plate upper crust (LPUC), orogenic wedge (OP), upper plate mantle (UPM) and upper plate crust (UPC). The shear zone is represented by a thicker line, which is dashed where the different underplating windows are located. The velocity field, as derived since $1.5 \mathrm{Ma}$ after widening of the underplating window below the TC, is shown. The main tectonostratigraphic units are represented. The Lishan Fault (LF) (Figure 1) is modeled as a vertical shear zone accommodating the differential uplift between the HR and the BS units. Our model predicts that the contact between the orogenic wedge and the backstop (LV and CoR) is a kinematic normal fault (Figure 5). Note that the vertical axis is not scaled for depths greater than $55 \mathrm{~km}$. (top) Predicted uplift and erosion rates over the Taiwan mountain belt, $U$ and $-e$, respectively, as derived from the equations of Figure 6.

[15] The thermal and rheological parameters assigned to the different domains are summarized in Tables 1 and 2 and were set either to standard values or values derived from local constraints. Radioactive heat production is considered uniform within the orogenic wedge. Thermal properties of the Cenozoic metasediments and of the pre-Tertiary basement are similar (see compilation of parameters by Song and Ma [2002] and Zhou et al. [2003]). We take into account the insulating effect of the thick sedimentary cover of the passive margin in computing the initial conditions of our model. No horizontal heat flow is allowed across the easternmost and westernmost boundaries. Surface and bottom temperatures are fixed to 0 and $1350^{\circ} \mathrm{C}$, respectively. The surface condition does not affect significantly modeled zircon (U-Th)/He and fission track ages. We only model the deformation and evolution of the Taiwan orogenic wedge. We do not account for the deformation across the whole plate boundary and in particular to the east within the CoR (backstop), so that the velocity $V_{1}$ represents underthrusting solely at the scale of the Taiwan mountain belt. We assume in our model a total shortening rate $V_{1}-V_{2}$ of $42 \mathrm{~mm} \mathrm{a}^{-1}$ across the orogenic wedge. However, we do not initially specify how this shortening rate is partitioned in terms of overthrusting $V_{2}$ and of underthrusting $V_{1}$ (Figure 6). In the case of the Himalaya of central Nepal, the spatial gradient of ${ }^{40} \mathrm{Ar}-{ }^{39} \mathrm{Ar}$ ages on muscovite allows for constraining $V_{2}$ because of the much broader scale of the system and because of the high obliquity of the $350^{\circ} \mathrm{C}$ isotherm to the particle trajectories and to the topographic surface [Avouac, 2003; Bollinger et al., 2004a]. A different line of reasoning is used here since these assumptions may not hold in Taiwan. Whether $V_{2}$ is positive (toward the east) or negative (toward the west) has implications for the internal kinematics of the wedge and for the geometry of the contact between 
the wedge and the backstop (Figure 5). We assume that the lithosphere not incorporated into the orogenic wedge subducts eastward below the Pacific plate. Lower crustal pure shear deformation might well contribute to crustal thickening beneath Taiwan but is ignored here, assuming it would only marginally affect the thermal P-T-t path of the rocks accreted to the orogenic wedge.

\subsection{Initial Conditions}

[16] A simple juxtaposition of the two plates without any shortening $\left(V_{1}=V_{2}=0\right)$, considering the different domains described above and taking into account an $8 \mathrm{~km}$ thick sedimentary layer on the passive margin side [Lin et al., 2003], is initially considered. Isotherms are allowed to relax until they reach close to steady state. The system described above and illustrated in Figure 7 is subsequently imposed.
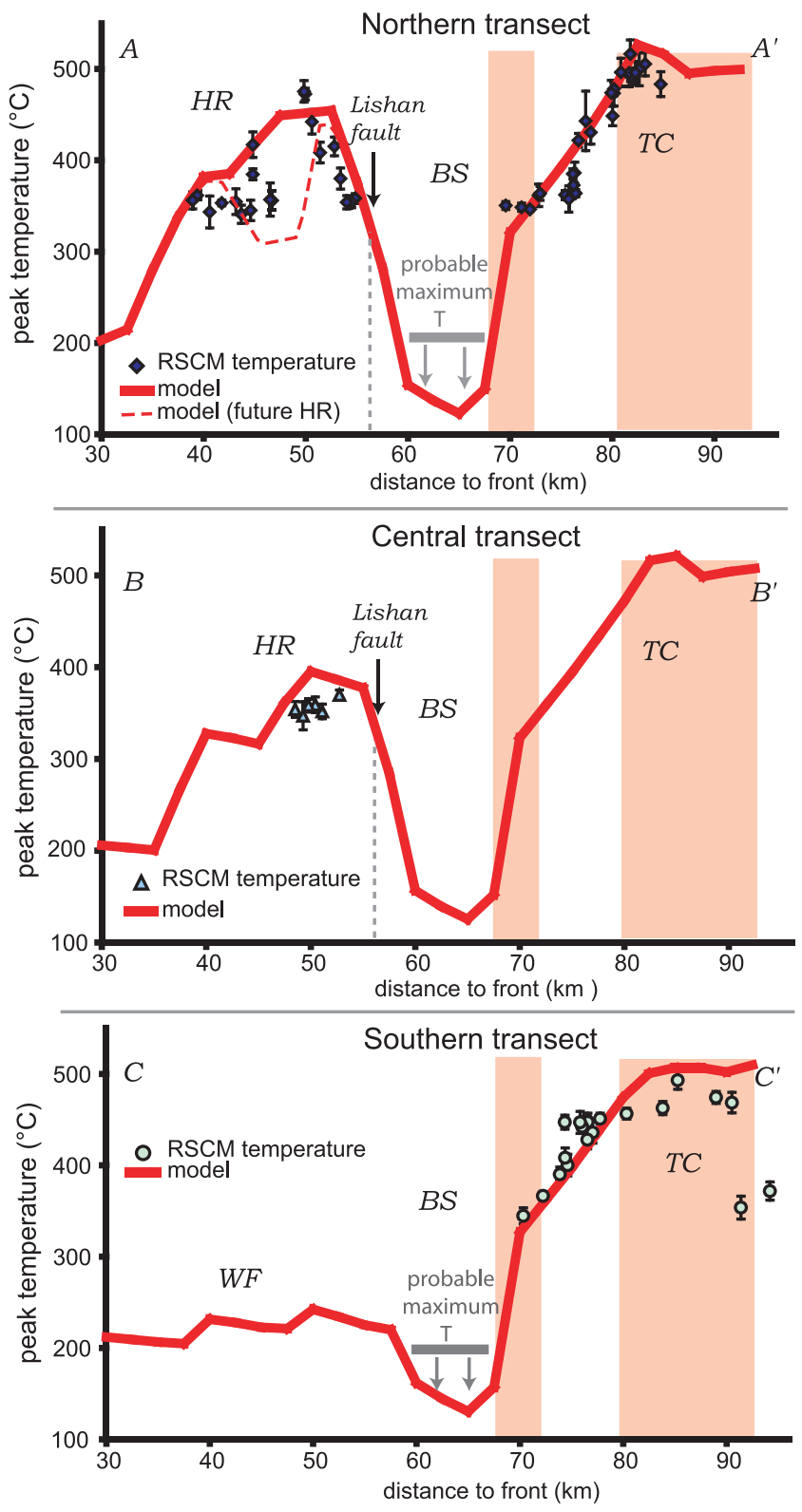

We do not model the initial oceanic subduction phase that prevailed in the past over Taiwan as seen farther south along the Manila Trench, because of the lack of data to constrain this earlier stage. In any case, given the total duration of our calculations $(t \sim 10 \mathrm{Ma})$, the total horizontal shortening rate $V_{1}-V_{2}$ and the considered thermal diffusivity $\kappa$ (Table 1 ), the Peclet number characteristic of our models is

$$
P e=\frac{\left(V_{1}-V_{2}\right)^{2} \cdot t}{\kappa} \approx 560
$$

indicating that heat advection is much more efficient than conduction. The characteristic time for thermal equilibration of the whole lithosphere is of $\sim 0.5 \mathrm{Ma}$. At the scale of the orogenic wedge, with exhumation rates expected to be as rapid as $\sim 6 \mathrm{~mm} \mathrm{a}^{-1}$, the Peclet number is $\sim 11.5$ and the characteristic time for equilibration over a depth of $\sim 30 \mathrm{~km}$ comparable to the probable maximum thickness of the wedge is $\sim 3.4 \mathrm{Ma}$. In any case, any eventual thermal record of the initial phase of oceanic subduction should be rapidly obliterated. This is consistent with the fact that temperatures within the wedge only change by less than $10^{\circ} \mathrm{C} \sim 4-5 \mathrm{Ma}$ after imposing the geometry and kinematics depicted in Figure 7 on the initial thermal condition.

\section{Forward Modeling of the Thermal Evolution of the Taiwan Mountain Belt}

[17] We present here a forward thermokinematic model of the Taiwan mountain belt. We solve for the thermal and temporal evolution of the wedge by adjusting model parameters to available metamorphic and thermochronological data. Some kinematic and geometric parameters are a priori poorly known. This is the case for the underthrusting and

Figure 8. Peak metamorphic temperatures measured from RSCM thermometry [Beyssac et al., 2007] and predicted by our thermokinematic model (red line) for the northern, central, and southern transects (Figure 1). Error bars represent a 2- $\sigma$ interval. A probable maximum temperature of $200^{\circ} \mathrm{C}$ is given over most of the BS for the northern and southern transects because most thermochronological ages are not reset (Figures 9 and 10) in this region. It is possible that this is also the case for the central transect, for which data are not available over the BS and TC. Shaded areas indicate where the model predicts peak metamorphic temperatures that were reached in the model during accretion to the wedge: this is the case for the high RSCM temperatures of $\sim 500^{\circ} \mathrm{C}$ over the eastern $\mathrm{TC}$, and for the temperatures of $\sim 350^{\circ} \mathrm{C}$ over the eastern BS units (Pilushan formation). Our model therefore suggests that most of the observed peak temperatures characterize the thermal structure of the passive margin (nonshaded regions). The dashed red line over the HR in the case of the northern transect indicates the pattern predicted for an additional $0.5 \mathrm{Ma}$ long period of underplating below this region. In this case, underplated rocks are exhumed at the surface and show lower peak temperatures of $\sim 300^{\circ} \mathrm{C}$ that are acquired during accretion to the orogen. 

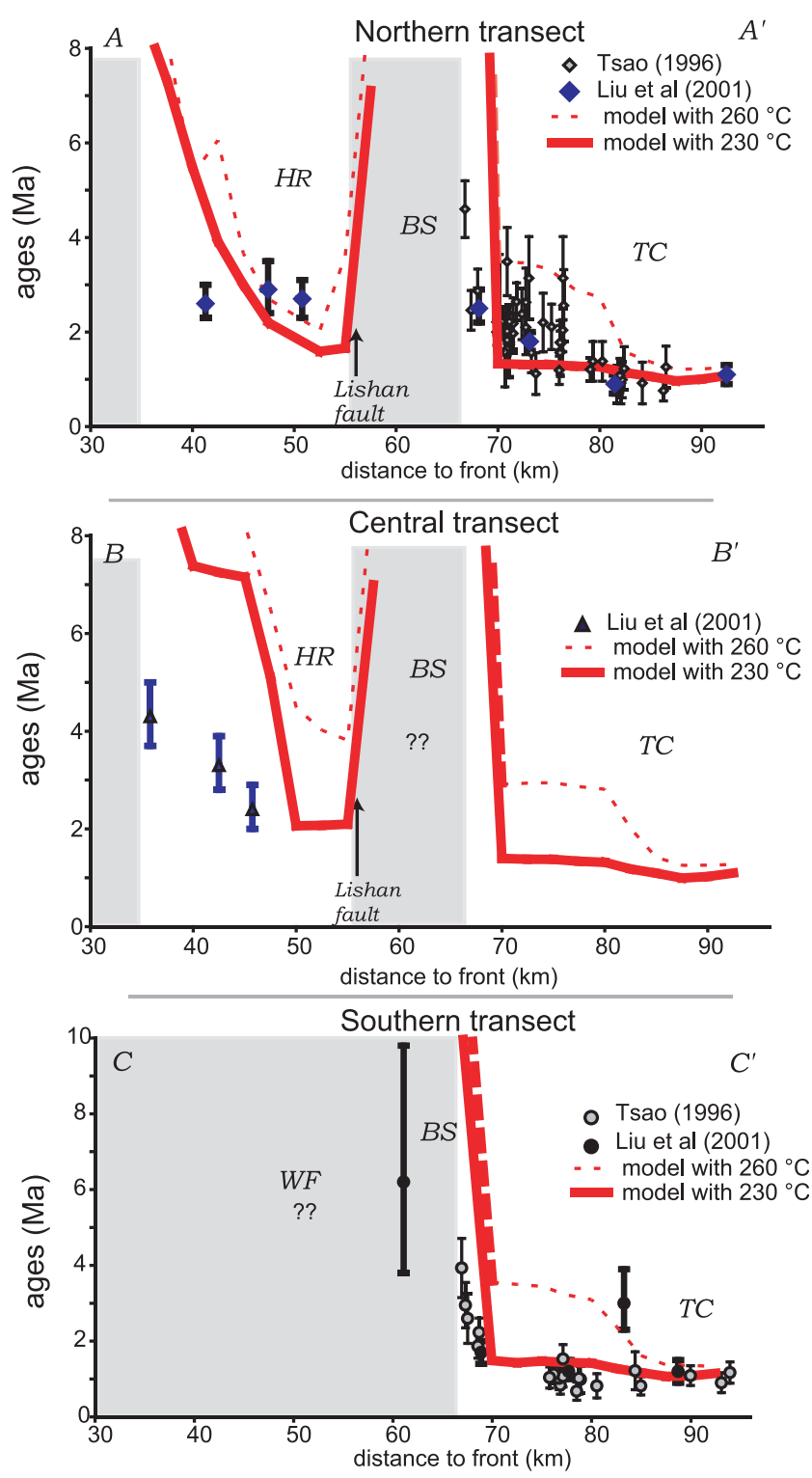

Figure 9. FT ages on detrital zircon from Liu et al. [2001] and Tsao [1996] with 2- $\sigma$ error bars and predictions from our thermokinematic model by assuming a closure temperature of $260^{\circ} \mathrm{C}$ (dashed red line) and $230^{\circ} \mathrm{C}$ (solid red line). Pooled ages are taken for the data from Tsao [1996]. In the case of the data from Liu et al. [2001], $\chi^{2}$ ages are considered. Shaded areas indicate where the ages are partially reset or nonreset. In the case of the central transect, no data are available for the BS and TC, and we assume that the extent of the area where ages are not reset is similar to that of the northern transect. Also data are not available over the WF of the southern transect, and we suppose that ages may be not reset or only partially reset.

overthrusting rates $V_{1}$ and $V_{2}$, the rate of underplating $V_{u}$ and of uplift $U$, the geometry of the basal shear zone and that of the contact with the backstop. We test and finally propose possible values and geometries that provide a thermal evolution of the mountain belt consistent with available data, as derived from the three documented transects reported on Figure 1. The southern and central cross-
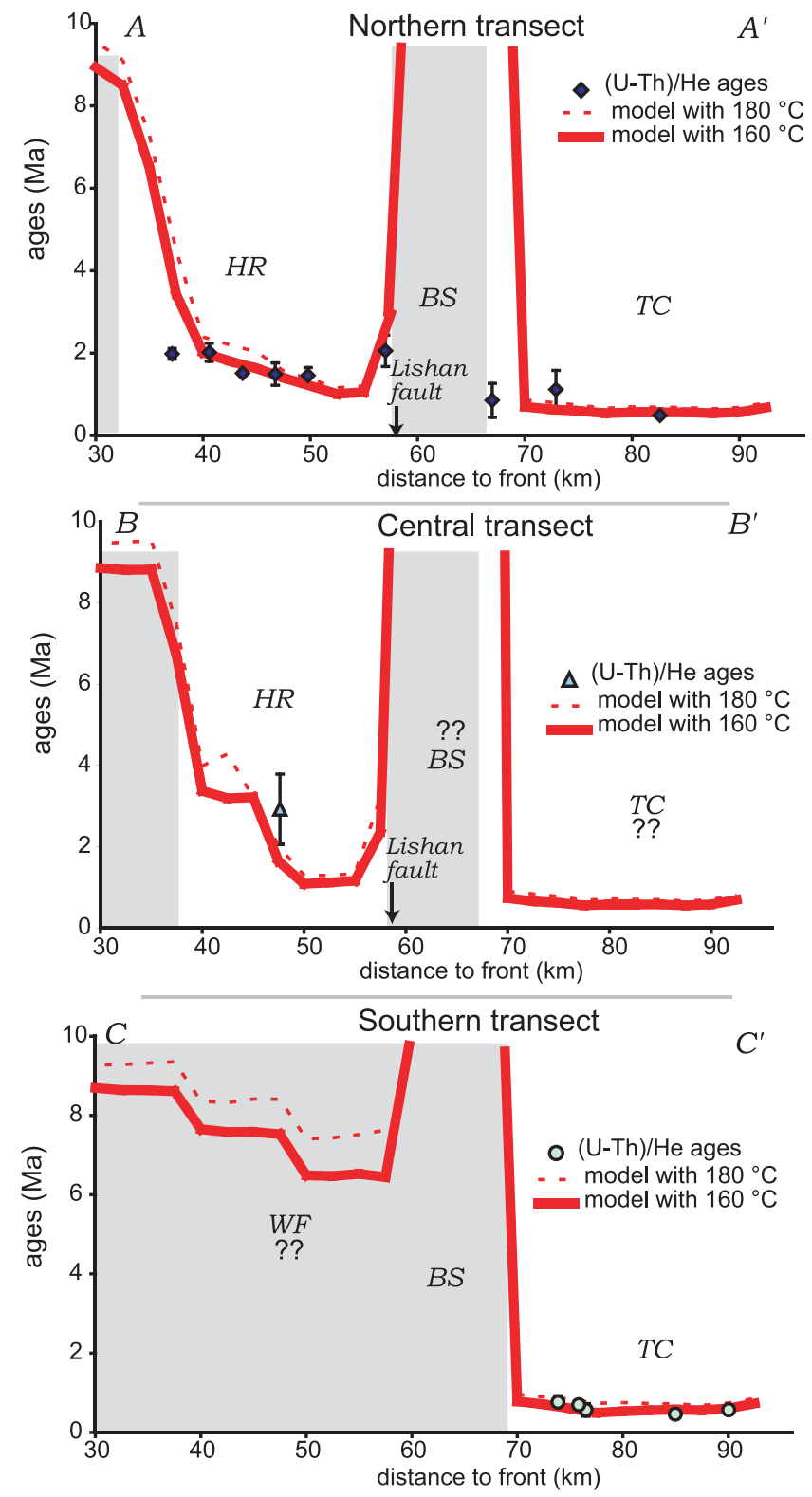

Figure 10. (U-Th)/He ages on detrital zircon [Beyssac et $a l ., 2007]$ with 2- $\sigma$ error bars and predictions from our thermokinematic model by assuming a closure temperature of $180^{\circ} \mathrm{C}$ (dashed red line) and $160^{\circ} \mathrm{C}$ (solid red line). Shaded areas indicate where the ages are partially reset or nonreset. In the case of the central transect, no data are available for the BS and TC, and we assume that the extent of the area where ages are not reset is similar to that of the northern transect. Also data are not available over the WF of the southern transect, and we suppose that ages may be not reset or only partially reset. The predicted peak metamorphic temperatures (Figure 8) over the WF along the southern transect suggest possibly reset ages, but there are no data to test this prediction.

island highways are our southernmost $\left(\mathrm{C}-\mathrm{C}^{\prime}\right)$ and northernmost $\left(A-A^{\prime}\right)$ sections, and the southern limit of exhumation of the HR along the Choushui river is our central transect $\left(\mathrm{B}-\mathrm{B}^{\prime}\right)$. 

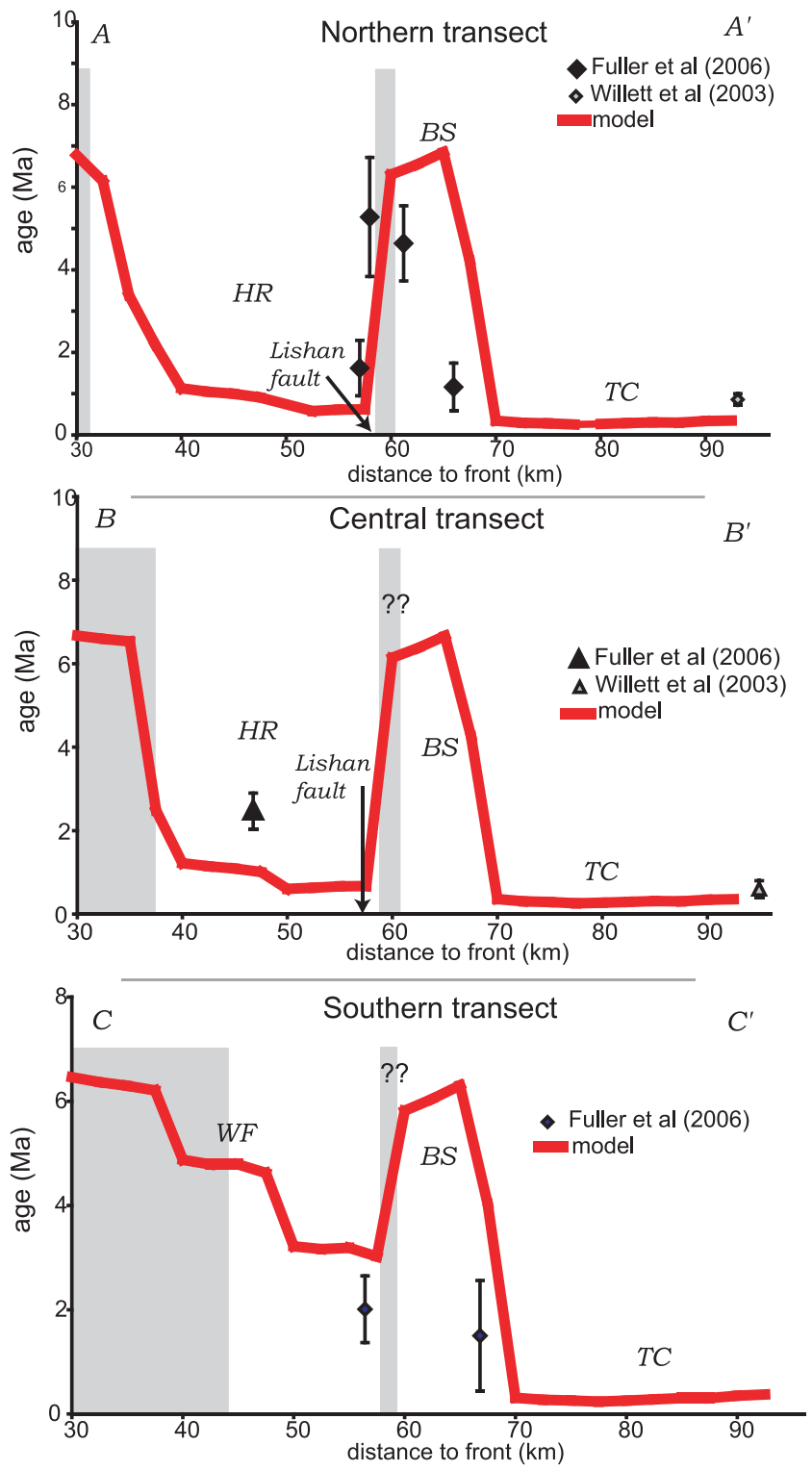

Figure 11. Measured FT ages on apatite [Fuller et al., 2006; Willett et al., 2003] and predictions of our model assuming a closure temperature of $100^{\circ} \mathrm{C}$ (red line). Shaded areas indicate the regions where ages are not reset. These regions are inferred in the case of the $\mathrm{BS}$ of the central and southern transects by comparison with observations from the northern transect and by analogy with what is obtained from other thermochronological ages (Figures 9 and 10).

\subsection{Overthrusting Rate Over the Taiwan Mountain Belt}

[18] The TC and eastern BS probably represent the most evolved structural units of the Taiwan mountain belt: basement rocks are exhumed and highly deformed, and no major north-south lateral changes can be detected in terms of metamorphic evolution (Figure 2). Therefore, as discussed in section 2.3, the thermal and structural evolution of these units may provide constraints into some of the model parameters. We find that underplating has to occur at depths of $\sim 30 \mathrm{~km}$ below the TC to reach the observed peak metamorphic temperatures of $\sim 500^{\circ} \mathrm{C}$ (Figure 2). Given a constant decollement dip angle at the base of the wedge, particle paths now exhumed as TC units cross the basal shear zone at greater depths if $V_{2}$ is negative than if $V_{2}$ is positive (Figure 5). Exhuming rocks that have been heated to temperatures of $\sim 500^{\circ} \mathrm{C}$ at depths of $30 \mathrm{~km}$ therefore requires that the dip angle of the basal decollement is more gentle for a negative $\left(\sim 17^{\circ} \mathrm{E}\right)$ than for a positive $(\sim 25-$ $30^{\circ} \mathrm{E}$ ) value of $V_{2}$. A negative overthrusting rate seems therefore more consistent with the proposed values for the decollement dip angle of $\sim 9-10^{\circ} \mathrm{E}$ [Carena et al., 2002] to $\sim 17^{\circ} \mathrm{E}$ [Simoes and Avouac, 2006]. Also it seems that a low value of $V_{2}$ can reasonably fit the data (less than $4 \mathrm{~mm} \mathrm{a}^{-1}$ in absolute value), which implies a steep dip angle for the contact between the backstop and the wedge, of the order of $\sim 65-70^{\circ}$ at least (Figures 5 and 7), consistent with geophysical constraints [Wu et al., 2007]. Such a steep angle is mechanically more compatible with a normal fault than with back thrust kinematics. We therefore favor a negative overthrusting rate within the Taiwan mountain belt, although a positive value, implying a west dipping fault bounding the orogen to the east (Figure 7), is commonly assumed [Fisher et al., 2007; Fuller et al., 2006].

[19] A good fit to the data (Figures 8-12) is obtained with $V_{2} \sim-2 \mathrm{~mm} \mathrm{a}^{-1}$ (and therefore $V_{1} \sim 40 \mathrm{~mm} \mathrm{a}^{-1}$
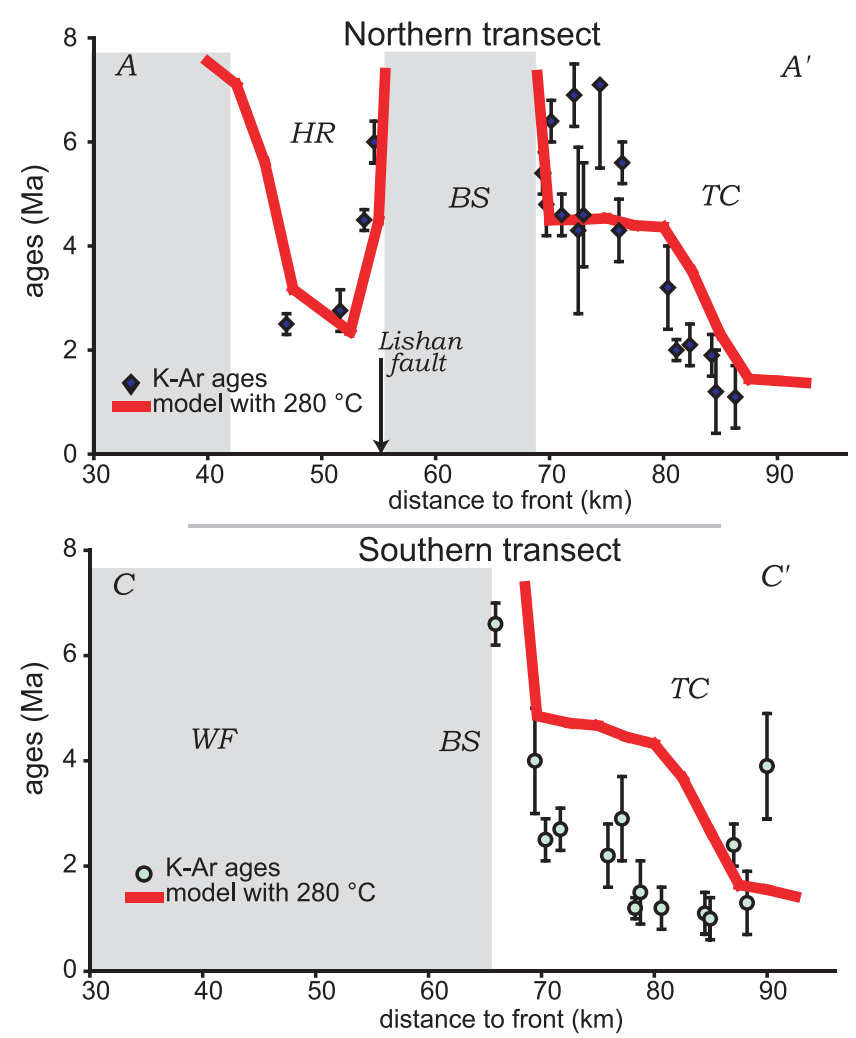

Figure 12. K-Ar ages on white mica fine fractions from Tsao [1996] with 2- $\sigma$ error bars and predictions of our thermokinematic model assuming a closure temperature of $280^{\circ} \mathrm{C}$ (red line). Shaded areas locate nonreset ages. In the case of the WF of the southern transect, data are not available to indicate whether or not these ages are reset. The location of nonreset ages drawn here is only supposed by comparison with model predictions. 


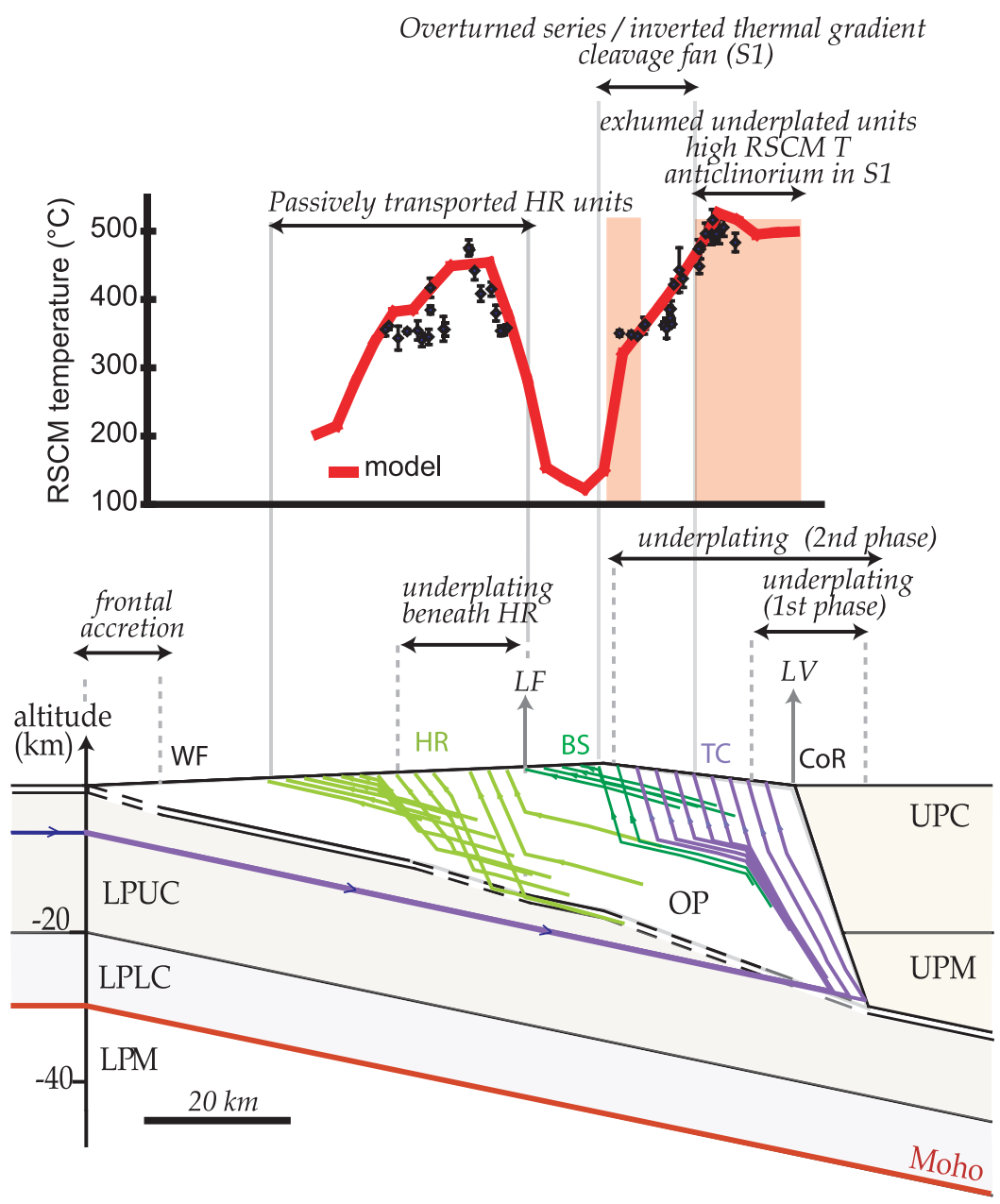

Figure 13. (bottom) Particle trajectories derived from our model for rocks presently at the surface along the northern transect. (top) Corresponding predicted and measured peak metamorphic temperatures with some of key structural observations. See Figure 7 for abbreviations.

given that $V_{1}-V_{2} \sim 42 \mathrm{~mm} \mathrm{a}^{-1}$ across the wedge). The value of this parameter is here essentially controlled by the gradients of RSCM temperatures and reset low-temperature cooling ages from the TC to the eastern BS. A negative value for $V_{2}$ geometrically implies that the contact between TC and the backstop is dipping to the east (Figures 5 and 7). Once $V_{2}$ and $V_{1}$ are fixed, the rate of underplating $V_{u}$ beneath the different tectonostratigraphic units is adjusted by changing locally the dip angle of the shear zone over the underplating windows (Figure 6).

\subsection{Metamorphism of the Tananao Complex}

[20] Metamorphism and exhumation of the TC can be accounted for with an underplating window along the basal decollement at the rear of the wedge (Figure 7). Predicted cooling ages are mostly sensitive to the rate of basal underplating $V_{u}$. Given the thermal structure produced by the set of the various other parameters, a value of $\sim 5.6 \mathrm{~mm}$ $\mathrm{a}^{-1}$ for $V_{u}$, implying a total uplift rate $U$ of $\sim 6.3 \mathrm{~mm} \mathrm{a}^{-1}$ (Figure 7), yields a good fit to the cooling ages (Figures $8-$ 12). The lateral extent of the underplating window has a significant impact on the predicted spatial distribution of peak metamorphic temperatures and of reset ages. A $\sim 40 \mathrm{~km}$ wide window below the TC provides a very good fit to the spatial extent of reset cooling ages. However, we are only able to reproduce the gradient of RSCM temperatures, decreasing from $\sim 500^{\circ} \mathrm{C}$ in the $\mathrm{TC}$ to less than $330^{\circ} \mathrm{C}$ in the BS, with a narrower underplating window of $\sim 15 \mathrm{~km}$. To solve for the inconsistency between the kinematics needed to fit the low-temperature cooling ages and peak metamorphic temperatures, we investigate the possibility of an underplating window that has widened over time. We find that if the width of this window increases from $\sim 15 \mathrm{~km}$ to $\sim 40 \mathrm{~km}$ about $1.5 \mathrm{Ma}$ ago (Figure 7 ) both data sets are reconciled (Figures $8-12$ ).

[21] We predict that the highest peak metamorphic temperatures of $\sim 500^{\circ} \mathrm{C}$ to the east have been acquired during underplating across the basal shear zone, and that the underplated rocks are now exhumed at the surface (Figures 8 and 13). Our model also suggests that the inverted gradient in RSCM temperatures observed over the western $\mathrm{TC}$ and eastern BS represents the thermal structure of the passive margin (nonshaded areas of Figure 8). Rocks that were underplated beneath this region over the last $1.5 \mathrm{Ma}$ were probably heated to high temperatures of $\sim 400$ to $500^{\circ} \mathrm{C}$ across the underplating window 

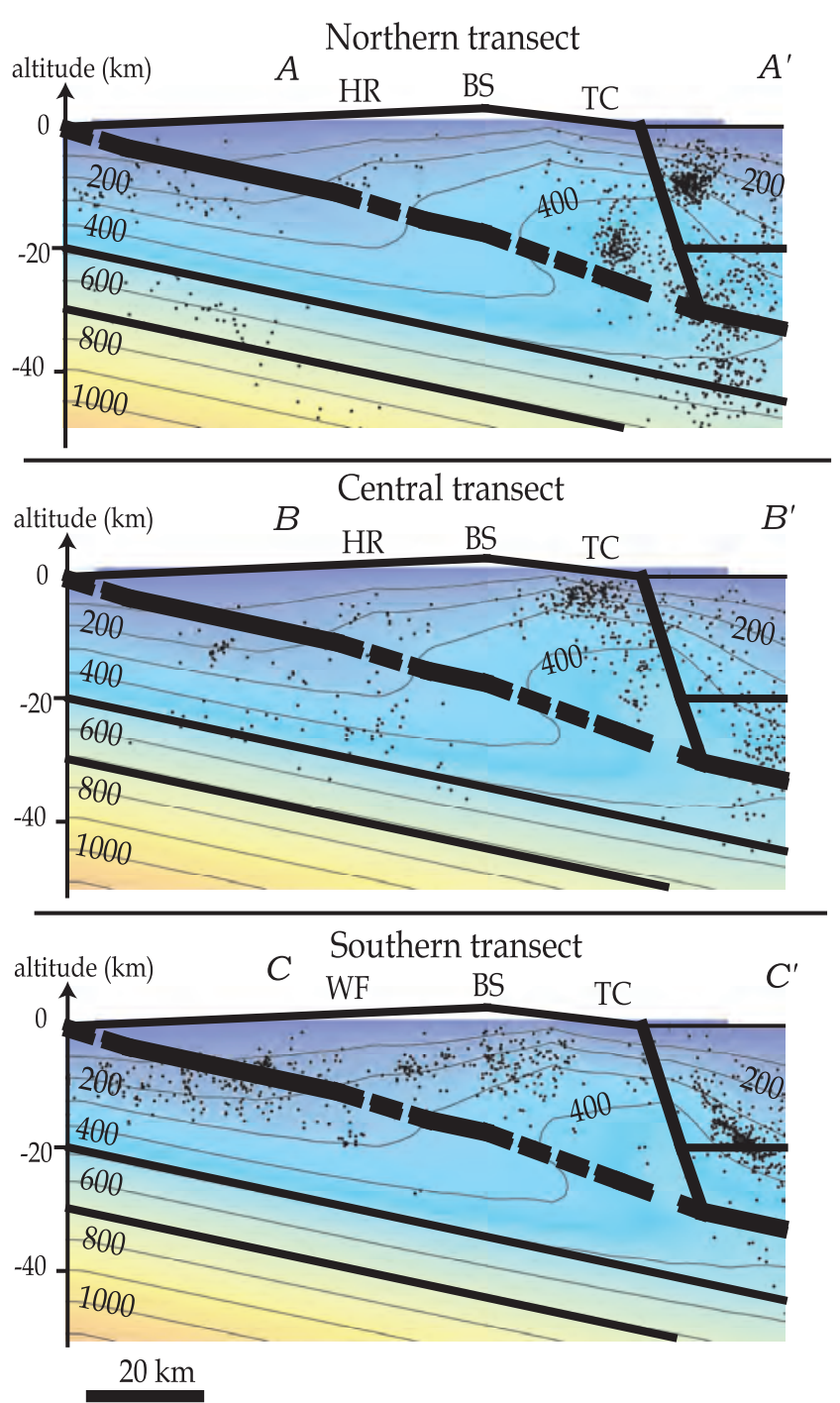

Figure 14. Predicted thermal structures for the three transects investigated in this study. Isotherms are represented by $100^{\circ} \mathrm{C}$ contours. Also shown is relocalized seismicity from $W u$ et al. [2007], retrieved along a $30 \mathrm{~km}$ wide swath centered along each one of the three transects located in Figure 1. Only the seismicity prior to the Chi-Chi earthquake from 1991 to September 1999 is plotted. The correlation of seismicity with topography and with the thermal structure, as noticed in earlier studies [e.g., Lin, 1998], holds to first order: a seismic gap seems to coincide with the high topography (except for the southern transect), and with the $350^{\circ}-400^{\circ} \mathrm{C}$ isotherms (except for the northern transect along the suture zone).

(Figure 14), but they have not yet been exhumed (Figure 13). Therefore the inverted thermal gradient across the BS and western TC as seen from RSCM temperatures is probably not a steady state feature. Because the inverted thermal gradient is advected westward at a rate $V_{2}$ over time, its location across the wedge is also a transient feature and the earlier kinematics correspondent to a narrow underplating window beneath the TC cannot be maintained for a too long period of time in our calculations. Different tests show that the model needs to keep running with such a narrow window for no more than $\sim 8-9$ Ma to fit the observed pattern of RSCM temperatures. Even though structures and exhumation are expected to be less evolved toward the south in Taiwan, this transient inverted thermal gradient between the TC and eastern BS units is similar in terms of temperature amplitude, gradient and location within the wedge on both the northern and southern transects (Figure 8). It appeared difficult to maintain the transient gradient on the northern section if any significant time lag between the two transects is introduced, even by allowing temporal changes in the geometry and rate of underplating. These findings therefore suggest that the laterally similar inverted thermal gradient (Figure 8) is indicative of a synchronous evolution of the TC and eastern BS rather than representative of a steady state in terms of exhumation. On the other hand, our model predicts that the lowtemperature cooling ages (FT and (U-Th)/He) are already at steady state in the sense of Willett and Brandon [2002], so that an exhumational steady state for these thermochronological systems may be achieved in less than 1.5 Ma. They therefore cannot be used as a record of the earlier history of exhumation and underplating below the TC.

\subsection{Modeling the Exhumation of the Hsueshan Range Units}

[22] Exhumation of the HR is documented by thermometric and thermochronological data retrieved on three transects across the wedge (Figure 1). Strong lateral changes in cooling ages and peak metamorphic temperatures represent the temporal evolution of this tectonostratigraphic unit, and indicate that it has not yet reached an exhumational steady state (Figures 8-12). The temporal evolution of the HR is reflected in the sedimentation history of the foreland basin and lateral distances can be converted into time by using the $\sim 31 \mathrm{~mm} \mathrm{a}^{-1}$ southward propagation rate of sediment depot centers in the basin [Simoes and Avouac, 2006] (Figure 4).

[23] The low $\mathrm{RSCM}$ temperatures $\left(<330^{\circ} \mathrm{C}\right)$ and the systematically nonreset cooling ages within most of the BS (Figures 2 and $8-12$ ) require that the underplating window beneath the TC does not extend farther west beneath the BS units. This provides constraints on the geometry of the basal shear zone. Given these, we find by eastward geometric continuity of the detachment beneath the TC that the underplating window beneath the HR lies at depths of $\sim 10$ to $\sim 18 \mathrm{~km}$ (Figure 7 ). On the basis of the same approach as for the TC, a $\sim 15 \mathrm{~km}$ wide underplating window and an uplift rate $U$ of $\sim 4.25 \mathrm{~mm} \mathrm{a}^{-1}$ (with $\mathrm{V}_{\mathrm{u}} \sim$ $3.6 \mathrm{~mm} \mathrm{a}^{-1}$ ) yield a good fit to peak metamorphic temperatures and cooling ages. In particular, these parameters and the $31 \mathrm{~mm} \mathrm{a}^{-1}$ rate of southward propagation can reproduce the southward decrease of exhumation of the HR (Figures 8-12), provided that underplating started beneath the $\mathrm{HR} \sim 4 \mathrm{Ma}$ before the stage represented by the northernmost transect (Figure 15). In this case, duplexing structures in the easternmost WF at the latitude of the town of Hsinying [e.g., Hickman et al., 2002; Hung et al., 1999], north of the Pingtung Plain, are probable equivalents of the earliest phases of underplating beneath the HR (Figure 15). Such temporal and kinematic scenario (Figures 7 and 15) is constrained so as to fit RSCM temperatures and (U-Th)/He 


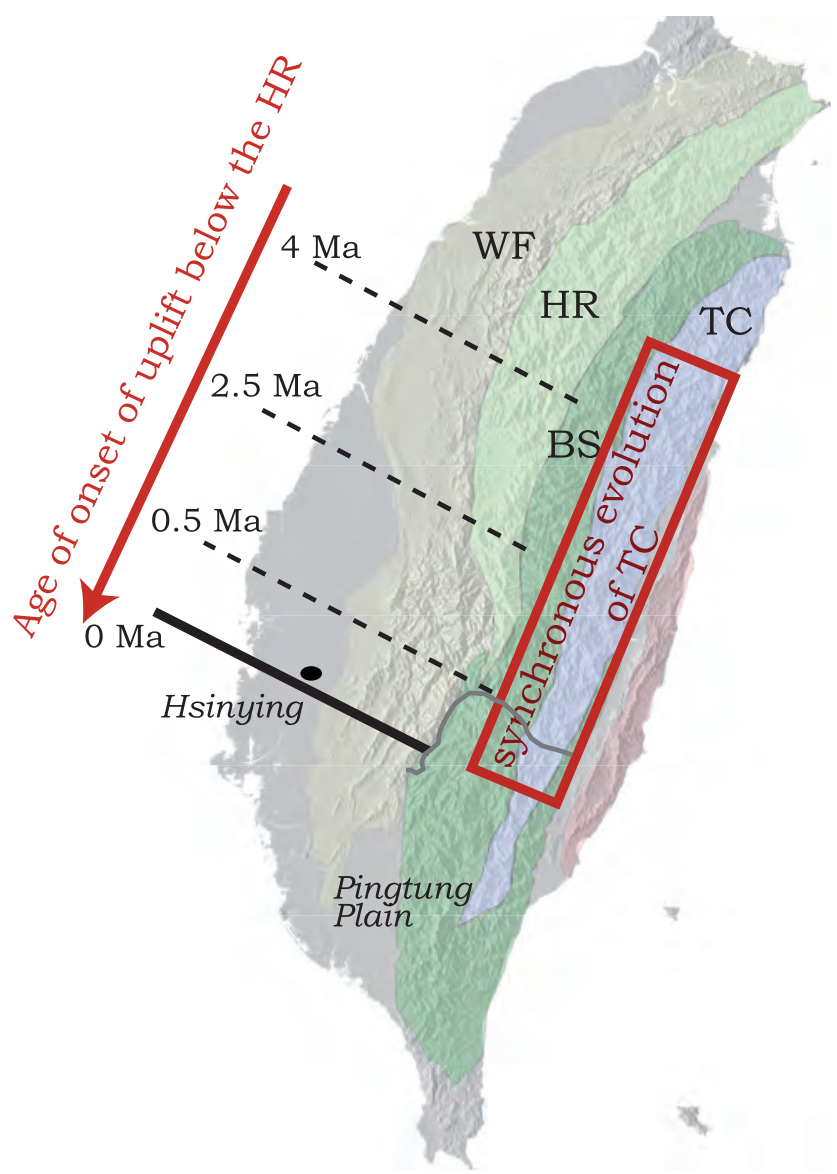

Figure 15. Sketch of the temporal evolution of the Taiwan mountain belt in map view. Our model suggests that the laterally similar pattern of peak metamorphic temperatures over the TC and the eastern BS (Figures 2 and 8 ) is indicative of the synchronous evolution of these series from south to north. On the other hand, the lateral variations in the exhumation of the HR units can be reproduced with a southward propagation rate of $\sim 31 \mathrm{~mm} \mathrm{a}^{-1}$.

ages. The model accounts adequately for the overall observed pattern of temperatures in the HR, although the nearly flat gradient in the western portion of the northernmost transect is not accurately reproduced (Figure 8). Also, the model implies that the RSCM temperatures within the HR represent the exhumed thermal structure of the passive margin sequences. The high peak temperature of $\sim 475^{\circ} \mathrm{C}$ is therefore not acquired during underplating but is rather related to the initial thick sedimentary sequences deposited prior to the collision in the basins of the Chinese passive margin, as proposed by Beyssac et al. [2007]. In the case of $(\mathrm{U}-\mathrm{Th}) / \mathrm{He}$ ages on zircons, there is not enough data along the Choushui transect to test the modeled temporal evolution of the HR (Figure 10). As for FT ages on zircon [Liu et al., 2001], the predicted ages are in the correct range of values although the fit is not excellent (Figure 9). We do not believe that this is critical to our model because the discrepancy observed between $\chi^{2}$ and pooled FT ages for samples from the HR [e.g., Beyssac et al., 2007] indicates a large variance in the annealing characteristics of the samples and questions the exact significance of these ages. The discrete stacking of thrust sheets beneath the HR needed to exhume the deep sedimentary units of the HR can therefore be modeled by assuming continuous underplating, although exhumation of the HR is not particularly longlived (Figure 15).

\subsection{Thermal Evolution of the Taiwan Mountain Belt}

[24] The timing of accretion through the different underplating windows is schematically represented on the map of Figure 15. Figures 8 to 12 compare the data with the predictions of our final model for the whole mountain belt in terms of peak metamorphic temperatures and cooling ages along the three transects. Note that a good fit to K-Ar ages on white mica fine fractions [Tsao, 1996] can only be obtained by assuming a closure temperature of $\sim 280^{\circ} \mathrm{C}$ at most (Figure 12), probably more realistic in the case of these data than the $350^{\circ} \mathrm{C}$ proposed in the source paper [e.g., Beyssac et al., 2007]. FT ages on apatite [Fuller et al., 2006; Willett et al., 2003] are not considered key to derive the evolution of the orogenic wedge because they are quite sensitive to surface conditions (temperature, relief..). Our model tends to predict FT ages on apatite consistent but slightly younger than the actual ages (Figure 11), in particular over the central and southern transects. This systematic trend may indicate that relief has increased in Taiwan over the last $\sim 1 \mathrm{Ma}$ [e.g., Braun, 2002], although this hypothesis needs to be more carefully tested.

[25] The temperature-time (T-t) history predicted for the Chipan gneiss within the TC to the north (Figure 1) and pressure-temperature-time (P-T-t) paths calculated for particles presently outcropping at the surface within the $\mathrm{TC}$, BS and HR units along the northernmost transect are represented in Figures 16 and 17. In the case of the higher temperature history predicted for the Chipan gneiss, our model fits relatively well the ${ }^{40} \mathrm{Ar}-{ }^{39} \mathrm{Ar}$ ages on biotite and on second-generation phengite flakes and amphibole reaction rims [Lo and Onstott, 1995]. These ages scatter around the predicted peak metamorphic conditions and timing. In the model, the rocks of the Chipan gneiss have been heated over a temperature of $\sim 400^{\circ} \mathrm{C}$ and up to $\sim 500^{\circ} \mathrm{C}$ over $\sim 3.5 \mathrm{Ma}$, and this short duration of peak temperature conditions could potentially explain the nonresetting of ${ }^{40} \mathrm{Ar}-{ }^{39} \mathrm{Ar}$ ages on coarse muscovites and amphiboles [Lo and Onstott, 1995]. We are also able to reproduce increasing temperatures along the particle path by $\sim 7 \mathrm{Ma}$, very close to the $6.5 \mathrm{Ma}$ age of initiation of the collision [e.g., Lin et al., 2003]. In any case, the model is relatively consistent with the available thermochronological data on the thermal history of the Chipan gneiss (Figure 16). The clockwise P-T-t path of TC units (Figure 17) indicates heating and subsequent rapid cooling. The maximum P-T conditions of $\sim 500^{\circ} \mathrm{C}$ and $\sim 8$ kbar are in the upper greenschist facies and are consistent for such lithologies with the observed mineralogy (muscovite, chlorite, albite, epidote and biotite) [e.g., Beyssac et al., 2007; Ernst, 1983]. However, the lack of clear index minerals in greenschist facies conditions for lithologies such as those encountered over the Taiwan mountain belt does not allow for clearly testing these P-T estimates from conventional petrology. $\mathrm{P}-\mathrm{T}$ paths for the BS and HR units suggest general cooling and decompression of these rocks from their initial conditions in the Chinese passive margin, although initiation of 


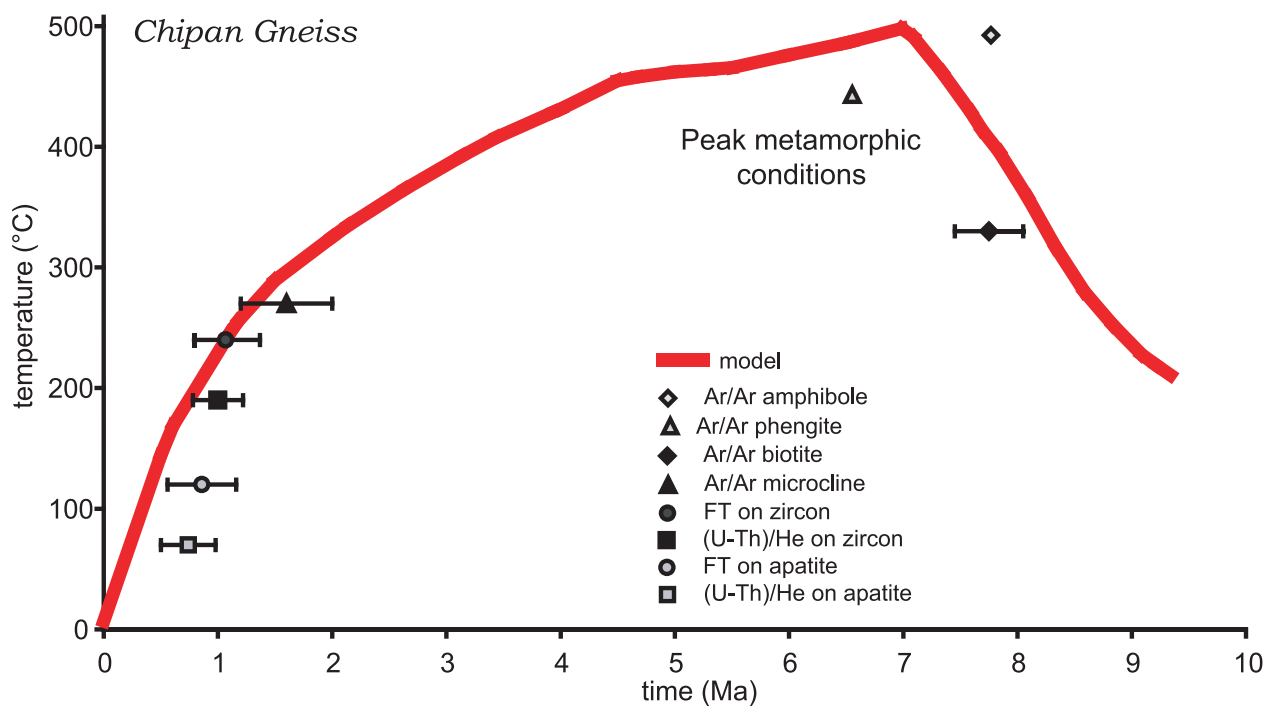

Figure 16. Time-temperature (T-t) path derived for the Chipan gneiss (eastern TC, northern transect, Figure 1) and model predictions (red line). The ${ }^{40} \mathrm{Ar} /{ }^{39} \mathrm{Ar}$ ages on biotite and microcline and ${ }^{40} \mathrm{Ar} /{ }^{39} \mathrm{Ar}$ age estimates for phengite flakes and for the reaction rims of amphiboles are from Lo and Onstott [1995]; FT $\left(\chi^{2}\right)$ age on zircon is from Liu et al. [2001]; (U-Th)/He ages are from Beyssac et al. [2007]; and FT (central) age on apatite is from Willett et al. [2003]. Error bars represent a 2- $\sigma$ uncertainty on the ages. Assumed closure temperatures are those proposed in the various source papers. Note that these different data were obtained from different samples collected from the Chipan gneiss massif.

underplating below the HR, $4 \mathrm{Ma}$ ago to the north, has slightly heated these rocks (Figure 17).

[26] Figure 14 shows the final thermal structures derived for the three transects. Temperatures within the orogenic wedge increase by $\sim 30^{\circ} \mathrm{C}$ at most from the southern to the central transect, and by $\sim 7^{\circ} \mathrm{C}$ at most between the central and the northern sections. Such variations in temperatures arise essentially from the late exhumation of the HR units. These results indicate that in Taiwan a thermal steady state may be approached very rapidly after only $\sim 3$ to $4 \mathrm{Ma}$, consistent with our estimate of the Peclet number at the scale of the orogenic wedge. Comparison of the thermal structures for the three transects indicates that the 2-D hypothesis inherent to our modeling approach holds for Taiwan.

\subsection{Sensitivity to Model Parameters}

[27] We test here the sensitivity of the model to different parameters to assess possible trade-offs. A negative overthrusting rate $V_{2}$ seems geometrically more reasonable as previously discussed. Its value controls the gradient of reset thermochronological ages and is essentially constrained by the cooling ages of the TC and eastern BS. A slight variation of this rate by $0.5 \mathrm{~mm} \mathrm{a}^{-1}$ to higher negative values significantly degrades the fit to the data. Predictions of high $\left(>330^{\circ} \mathrm{C}\right)$ RSCM temperatures and reset cooling ages are advected westward by $\sim 10 \mathrm{~km}$ from the actual observations. The gradient of peak metamorphic temperatures slightly steepens, and the gradient of thermochronological ages significantly increases when compared to data $\left(0.15 \mathrm{Ma} \mathrm{km}^{-1}\right.$ along section for (U-Th)/He ages over western TC and eastern BS, to be compared to the observed value of $0.05 \mathrm{Ma} \mathrm{km}^{-1}$ ). Changes of $V_{2}$ to lower negative values do not impact as much the fit to the data. Similarly, the width and position of the underplating windows locate the areas where uplift is highest so that they are fixed by the location and lateral extent of observed reset ages. We tested different underthrusting rates $V_{1}$ by varying the total shortening rate $V_{1}-V_{2}$ between 39 and $45 \mathrm{~mm} \mathrm{a}^{-1}$, with $V_{2}$ fixed to $-2 \mathrm{~mm} \mathrm{a}^{-1}$. Variations in $V_{1}$ do not affect much the thermal structure of the range and the peak metamorphic temperatures, but significantly influence the underplating rate $V_{u}$ and therefore predicted cooling ages. Adjusting $V u$ to the possible different values of $V_{1}$ requires that the local dip angle of the underplating window is significantly modified (Figure 6). A trade-off therefore exists between $V_{1}$ and the local dip angle of the basal shear zone over underplating windows. The rate of southward propagation of the exhumation of the HR units affects the time lag between the three investigated transects. We have tested the possible extreme rates of 41 and $26 \mathrm{~mm} \mathrm{a}^{-1}$. A slower propagation rate implies a greater time lag between the different sections. This does not affect much the predictions for the northern transect, provided that a total duration of $\sim 4 \mathrm{Ma}$ for the exhumation of the HR to the north is maintained (Figure 8). However, in this case, peak metamorphic temperatures for the central transect are too high and cooling ages are too young. The opposite is observed for faster propagation rates. Indeed, the rate of $31 \mathrm{~mm} \mathrm{a}^{-1}$ accounts quite well for the along-strike variations in the exhumation of these units.

[28] The thermal structure is not significantly affected by kinematic parameters but is most sensitive to radioactive heat production and to shear heating. Our preferred model described above considers a production rate of $1.7 \mu \mathrm{W} \mathrm{m} \mathrm{m}^{-3}$ based on the average value measured from the various lithologies encountered across the mountain belt (see compilation of data of Chang [1989] by Song and Ma [2002]) 

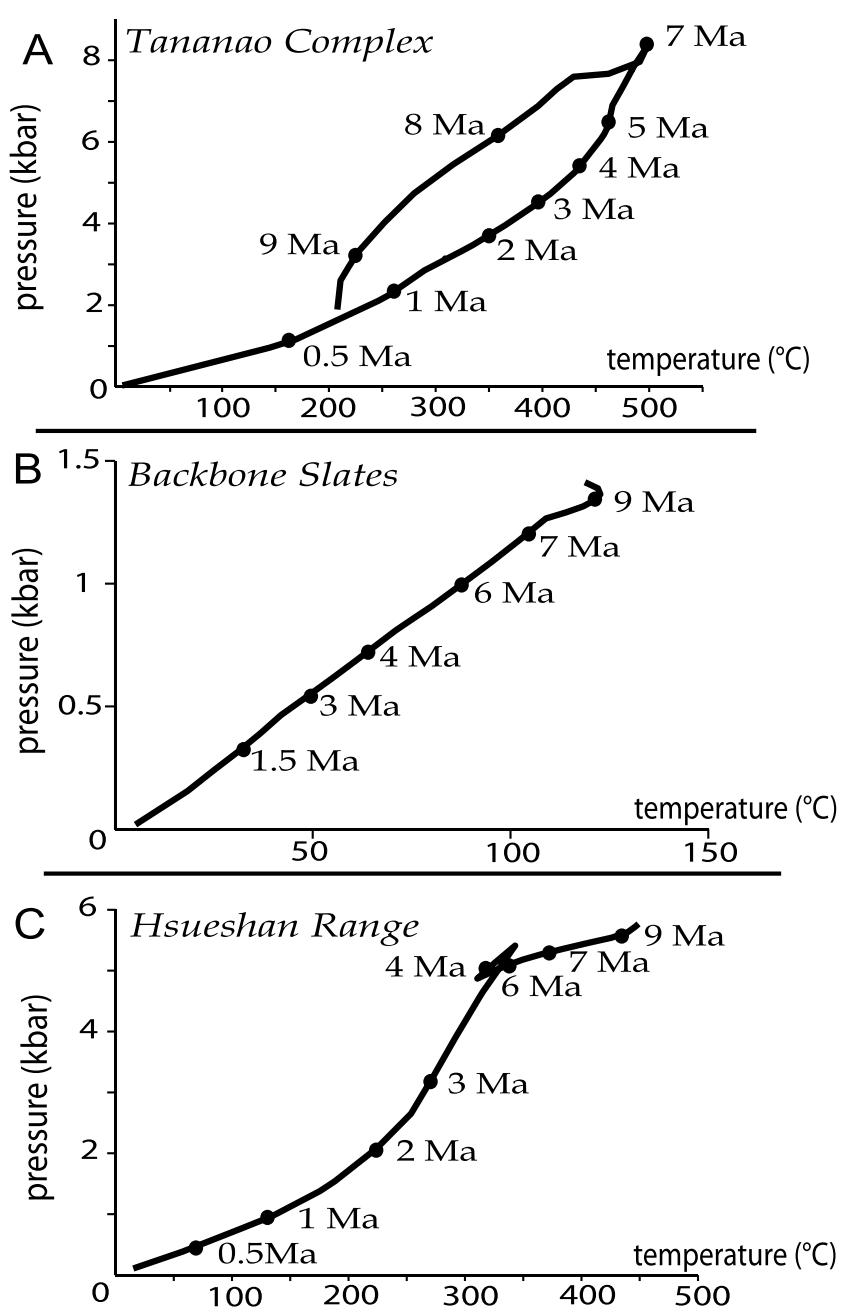

Figure 17. P-T-t paths predicted along the northern transect, and more specifically for (a) the Chipan Gneiss within the TC (Figure 1), (b) the BS, and (c) the core of the HR units. Only the more internal portions of the Taiwan mountain belt, underplated and now exhumed as TC units (Figure 13), were significantly heated during the last orogeny. The BS and HR have simply cooled down from their temperatures within the initial passive margin. Note that the pressure scale is different for the three graphs.

(Table 1). A rate of $1 \mu \mathrm{W} \mathrm{m}$ m $^{-3}$ was used by Barr and Dahlen [1989], while values as high as $2.45 \mu \mathrm{W} \mathrm{m}^{-3}$ were measured from basement rocks along the Pearl River Mouth [Rao and Li, 1994]. These two extreme rates were tested. A higher radioactive heat production leads to slightly higher peak metamorphic temperatures (by $\sim 10^{\circ} \mathrm{C}$ for the tested values) and significantly younger predicted cooling ages (by $\sim 0.5 \mathrm{Ma}$ ). In the case of shear heating, a diabase rheology for the shear zone, with a maximum shear stress of $100 \mathrm{MPa}$, also increases peak temperatures by $\sim 20^{\circ} \mathrm{C}$ and cooling ages are too young for the TC and HR. These increases in the radioactive heat production and in the shear heating can be compensated by an upward shift of the basal shear zone, and by lowering the rate of underplating. We acknowledge that the model we propose is nonunique and that changes in the thermal parameters may be adjusted by modifying the geometry of the system and some of the kinematic param- eters. However, we consider it to be a reasonable model that assumes a realistic amount of shear heating and satisfies available constraints on radioactive heat production, kinematics of crustal deformation and subsurface geometry.

\section{Discussion and Model Implications}

5.1. Structure of the TC and Eastern BS: Significance of the Cleavage Fan and of the Inverted Thermal Gradient

[29] Particle trajectories predicted for rocks presently lying at the surface are shown in Figure 13. The model accounts well for stratigraphic continuity between and within the Miocene BS and the Eocene to Oligocene HR units. It also predicts that the series of the eastern $\mathrm{TC}$ and western BS are overturned (Figures 13 and 18), as observed in the field in this area. Bedding ( $\mathrm{S} 0$ ) is hardly distinguishable within the most deformed portion of the eastern TC, but can be observed within the other units, essentially by following stratigraphic contacts between sandstone and slate beds. The westernmost portion of the TC and the overall BS have S0 dipping to the east [Beyssac et al., 2007; Ernst, 1983; Tillman and Byrne, 1996]. Also, although clear polarity criteria are hardly recognizable in the field, overturned conglomerates of the BS have been locally described to lie unconformably over the TC basement [Suppe et al., 1976] and indicate that the contact between the two units is stratigraphic and that the series is overturned in this area. This is also supported by the field investigations of Ernst [1983], who documented overturned clastic textures within the whole eastern BS. Alternatively, it has also been proposed that the TC basement overthrusts the slate belt [Fisher et al., 2002]. However, no major break is observed across the western TC and BS in terms of metamorphism and cooling ages (Figure 2), suggesting that little dip-slip motion, if any, occurred on the contact separating the TC and BS, as assumed in our model. It should be noted here that the observed overturned series correspond in our model to the transition between underplated and passively transported rock units forming the roof of the underplated duplex system (Figure 13). We do not observe in our model a regional overturned slab at the rear of the wedge, as schematically depicted in Figure 5 in the case of a negative overthrusting rate. This is probably because in Taiwan underplating has not been sustained for long enough to exhume all units accreted at depth. This is in particular true for the rocks underplated below the western TC since 1.5 Ma, as illustrated in Figure 13. In any case, because accretion of thrust sheets is probably a discrete process, it should be still possible to preserve locally normal stratigraphic series within accreted duplexes in the case that $V_{2}$ is negative.

[30] Deformation fabrics within the orogen have been documented in a number of studies [e.g., Clark et al., 1993; Crespi et al., 1996; Faure et al., 1991; Fisher et al., 2002; Pulver et al., 2002; Tillman and Byrne, 1995] and are generally interpreted to reflect the late Tertiary orogeny [e.g., Ernst, 1983; Pulver et al., 2002]. In the easternmost TC units, where our model predicts that the rocks reached a peak temperature of $\sim 475$ to $500^{\circ} \mathrm{C}$ during underplating (Figures 8), the schistosity (S1) forms an anticlinorium [Faure et al., 1991; Pulver et al., 2002] (Figure 1). This 
Retrodeformed section

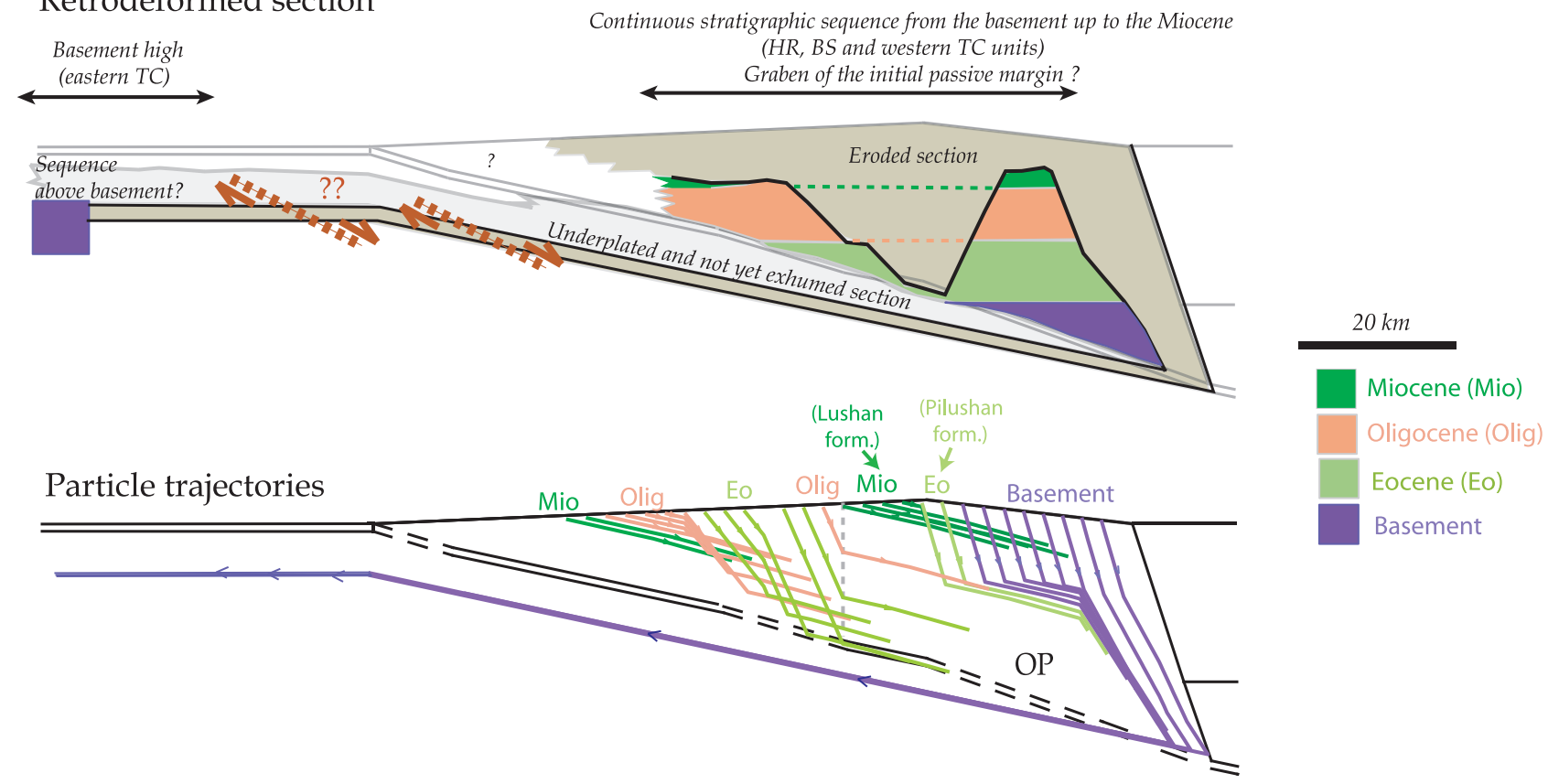

Figure 18. (bottom) Predicted particle trajectories for rocks now at the surface. (bottom) Corresponding retrodeformed section of the Taiwan mountain belt. The different colors for the trajectories and for the reconstructed section represent the different stratigraphic ages derived from the geological map of Taiwan [Ho, 1986, 1988]. The retrodeformed section is obtained from the predicted initial location of the rocks presently outcropping at the surface. No major discontinuity is observed between the HR and BS units, and we propose that they were probably deposited in a graben of the Chinese passive margin. On the other hand, the initial depth of the eastern TC basement is shallower than that of the basement initially below the HR and BS sedimentary sequences (now forming the western TC), and we propose that it may have been a horst of the margin.

anticlinorium could simply reflect folding of the earlier fabrics, associated with the development of a duplex system at depth as rocks are accreted beneath the TC (Figure 13). A crenulation cleavage (S2) has been reported locally in the western limb of this anticlinorium along the northern transect [Pulver et al., 2002], and over most of it in the case of the southern transect [Crespi et al., 1996]. These studies suggest that $\mathrm{S} 2$ formed roughly at $\sim 40-45^{\circ}$ to $\mathrm{S} 1$, indicating a rotation of the fabrics with respect to the stress field within the wedge. This value of $\sim 40-45^{\circ}$ is lower than the $\sim 90^{\circ}$ expected in the case of a doubly vergent wedge model [Fisher et al., 2007]. In the framework of our model, the crenulation cleavage could reflect the reorganization of the stress and strain field that must have occurred as underplating beneath the TC increased $\sim 1.5 \mathrm{Ma}$ ago (Figure 13). Farther west within the TC, the cleavage (S1) progressively changes from a west to an east dipping direction (e.g., Pulver et al. [2002] for the northern transect and Crespi et al. [1996] for the southern transect) (Figure 1). In the westernmost TC units and in the whole BS, S1 maintains a plunge toward the east and is subparallel to bedding S0. The cleavage fan has been interpreted to reflect a rotation in the orientation of the principal stresses between the prowedge and retrowedge of a doubly vergent orogen [Fisher et al., 2007]. We note that the cleavage fan coincides with most of the inverted thermal gradient across the western TC units. In our model, its location corresponds to the transition between exhumed underplated rocks and basement cover units that were transported passively to the west over the duplex (Figure 13). This transition coincides with a subvertical fault described in the field by Ernst [1983]. The cleavage fan and inverted thermal gradient may therefore be simply related to the transition between the folded schistosity of exhumed duplexes to the east and the east dipping S1 of rocks that have been passively transported to the west. Our model thus provides an alternative interpretation of the cleavage fan to that of Fisher et al. [2007]. Note that we do not attribute the inverted thermal gradient to a particular fault but simply to distributed tectonic shear at depth, as also proposed for the inverted gradient observed in the Nepal Himalaya [Bollinger et al., 2006]. An overall top-to-the-west sense of shear has been observed in the TC and eastern BS rocks, with increasing pervasive deformation toward the east [Clark et al., 1993; Faure et al., 1991; Fisher et al., 2002; Tillman and Byrne, 1995], reflecting the possible progressive eastward increasing exhumation of the duplex system (Figure 13). Our model predicts that in the BS the Eocene Pilushan formation was transported over the Miocene Lushan formation (Figure 18). The contact between these two units may be hardly recognizable in the field because of their similar lithologies, but has been reported in the case of the southern transect [Tillman and Byrne, 1995].

\subsection{Uplift and Exhumation of the HR Units: Underplating or Distributed Shortening?}

[31] The differential uplift between the HR and BS units, as revealed by the thermometric and thermochronologic 
data (Figures 2 and 8-12), is accommodated in our model by vertical shear along the morphologically well expressed Lishan Fault (Figures 7 and 13). In our model, uplift of the Hsueshan Range is the result of underplating, a mechanism which accounts for the general anticlinal structure of the HR units (Figure 18). Underplating was favored because of the lack of evidence of active shortening across the HR [Simoes and Avouac, 2006] and because of previous structural interpretations suggesting duplex systems beneath the Hsueshan Range and beneath the internal southwestern Foothills [Powell, 2003; Hickman et al., 2002; Hung et al., 1999; Mouthereau et al., 2001; Suppe, 1980; Yang, 2007]. According to our model, the rocks observed presently at the surface have just been passively transported and uplifted above the underplated thrust sheets, which is consistent with the absence of significant noncoaxial deformation [Clark et al., 1993; Tillman and Byrne, 1995] (Figure 6). Predicted particle trajectories suggest that the underplating window has been active long enough to nearly exhume the underplated thrust sheets along the northern transect (Figure 13). We noticed that if underplating below the HR is increased in the model, so as to bring to the surface underplated units, the fit to the data degrades. In particular it yields peak metamorphic temperatures underestimated when compared to RSCM data (Figure 8, top). Clearly, the HR units have not yet attained an exhumational steady state.

[32] The subvertical and axial planar foliation with in the HR units [Clark et al., 1993; Fisher et al., 2002; Tillman and Byrne, 1995] does however provide evidence for some penetrative deformation (Figure 1). Given that in our model the duplex system beneath the HR has not yet been exhumed, the kinematics that we propose does not provide a direct explanation for the observed deformation within the HR. It is possible that thickening of the HR units related to shortening may in part explain the locally larger cumulative exhumation and exhumation rates. The alternative view would be that all the uplift within the HR would have resulted only from internal shortening within the wedge. Given that the decollement lies at a depth of $\sim 12 \mathrm{~km}$ beneath the Hsuehshan Range (Figure 7), mass balance requires that the $\sim 4.2 \mathrm{~mm} \mathrm{a}^{-1}$ exhumation rate over the $\sim 15 \mathrm{~km}$ wide uplifted HR units be compensated by $\sim 5.2 \mathrm{~mm} \mathrm{a}^{-1}$ of horizontal shortening. This possibility cannot be ruled out given the uncertainties on the total shortening rate across the wedge and on the slip rates of active thrust faults of the foothills [Simoes and Avouac, 2006].

[33] Ductile strain measurements indicate coaxial deformation within the foliation with a 1.5 to 4.3 elongation [Clark et al., 1993; Fisher et al., 2002; Tillman and Byrne, 1995]. If it applies uniformly to the whole HR, this elongation would suggest more than a doubling of crustal thickness related to strain. This makes it possible that part of the exhumation required by the thermometric and thermochronological data be related to distributed shortening within the HR units. However, it should be pointed out that finite strains were only retrieved from pyrite porphyroids in slate interbeds and that sandstone layers, which constitute most of the core of the HR units, are only weakly to moderately deformed [Tillman and Byrne, 1995]. Also, the highest measured elongations of 4.3 were obtained within the western portion of the core of the HR, where RSCM temperatures and (U-Th)/He ages are lowest and older, respectively (Figures 8 (top) and 10 (top)), whereas the lowest values of 1.5 to the east correspond to where exhumation has been more intense [Tillman and Byrne, 1995, Figure 7]. In fact, this anticorrelation between finite strains and exhumation indicates that shortening is not the major mechanism for exhumation within the HR. We have shown in this study that the overall pattern of peak metamorphic temperatures (Figure 8) and cooling ages (Figures 9-12) can be reproduced with continuous underplating over the last $4 \mathrm{Ma}$. In that scenario, shortening across the HR has been minor over the last $4 \mathrm{Ma}$, and the coaxial deformation fabrics would need to have formed in an early stage of deformation not accounted for by our model (see section 5.9). In any case, we acknowledge that our model is nonunique and that other kinematic scenarios can possibly also explain the exhumation of the HR.

\subsection{Initial Geometry of the Underthrust Chinese Continental Margin}

[34] From the predicted trajectories of rocks now outcropping at the surface, it is possible to reconstruct the initial position of the deformed basement and sedimentary sequences now outcropping at the surface (Figure 18). We use the stratigraphic age of rocks at the surface based on the geological map of Taiwan [Ho, 1986, 1988] and bring them back to their initial position $\sim 9$ to $10 \mathrm{Ma}$ ago as predicted by our kinematic model. The restored section suggests that the BS and HR units were initially deposited in the same basin (Figure 18), and that the deeper Eocene and Oligocene units were mostly transported westward and exhumed to form the present HR, whereas most of the Miocene shallow marine strata were slowly exhumed at the level of the BS. Exception to this is the Eocene Pilushan formation that forms an overturned series along with the western TC (Figure 18). This scenario is in contrast with the wellaccepted idea that the BS and HR units represent a former horst and graben, respectively, separated by the Lishan Fault [e.g., Clark et al., 1993; Lee et al., 1997; Teng, 1992; Teng et al., 1991]. This earlier interpretation was proposed to account for the differences observed between the HR and BS units in terms of stratigraphy and sedimentary facies [Teng, 1992; Teng et al., 1991], and in terms of styles of deformation [Clark et al., 1993]. Also, the missing Oligocene sequence between the Miocene and Eocene of the BS units has been interpreted as a sedimentary hiatus comforting the idea that the BS was initially a basement high [Teng et al., 1991]. Our model indicates that this hiatus is only apparent because the Oligocene units beneath the Miocene rocks of the BS were transported westward and now crop out within the HR (Figure 18). Our model also predicts that the Eocene Pilushan formation is transported over the Miocene rocks of the BS, as also supported by the tectonic contact observed between these units [Tillman and Byrne, 1995]. We propose here an alternative scenario that reconciles stratigraphic and structural observations for the HR and BS units. Underplated basement rocks forming the anticlinorium in the eastern TC are predicted to have been originally west of the Eocene to Miocene basin. More particularly, as illustrated in Figure 18, they are expected to have constituted a horst in the Chinese passive margin because their predicted 
initial position is shallower than that of the basement beneath the HR and BS basin (now outcropping in western TC). Some normal faults may have separated this basement high from the adjacent basin (Figure 18). It is possible that such structures subsequently played a key role in the structural evolution of the range (localization of the basal decollement or of the different underplating windows). The differences in the spatiotemporal evolution of the TC and HR units, as seen from various sections across the orogen, might be related to this initial architecture of the passive margin: it is possible that the basin formed of HR and BS units may have been more oblique to the direction of convergence than the basement horst. Our model therefore provides a new paleogeographic and tectonostratigraphic interpretation of the sequences accreted to the Taiwan mountain belt.

\subsection{An East Dipping Normal Contact Between the Mountain Belt and the Longitudinal Valley?}

[35] The nature of the contact between the Taiwan mountain belt and the backstop has been controversial in the literature and no clear geophysical constraints allow for discriminating the different possibilities [e.g., Kim et al., 2005; McIntosh et al., 2005]. A west dipping back thrust has been proposed from the interpretation of the topographic slope based on a critical wedge approach [e.g., Carena et al., 2002; Suppe, 1981], or from the analysis of deformed terraces along the eastern flank of the mountain belt along the LV [Shyu et al., 2006b]. Fisher et al. [2007] also propose that a doubly vergent wedge is consistent with the observed crenulation cleavage and cleavage fan of the eastern and western TC units, respectively. However, as discussed in the previous sections, interpretation of this deformation fabric is not unique. Three-dimensional highresolution $\mathrm{V}_{\mathrm{p}}$ and $\mathrm{V}_{\mathrm{s}}$ tomography indicates that the contact with the backstop is subvertical $\left(\sim 70-80^{\circ}\right)[W u$ et al., 2007]. Such steep geometry seems more realistic in the case of a kinematic normal fault than in the case of a back thrust. Evidence for brittle to ductile E-W extensional strain along the eastern TC is reported by Crespi et al. [1996], in keeping with an east dipping extensional contact along the eastern flank of the TC. In this study, we also argue for an east dipping normal fault geometry because it can account for the high peak metamorphic temperatures of the TC with a reasonable dip angle of the basal decollement and for the observed inverted thermal gradient. We realize that our arguments are not particularly compelling, but in the absence of any other clear constraints, a kinematic normal fault on the eastern flank of the orogen provides a reasonable fit to the structural and thermal evolution of the mountain belt. In any case, we acknowledge the possibility that the geometry of this contact is particularly complex and that it has evolved over time probably from a back thrust to a normal fault, as suspected from structural and geological observations [Malavieille et al., 2002] or from geophysical investigations to the south of Taiwan and across the more mature orogenic structures of the mountain belt [McIntosh et al., 2005]. Such evolution has been reproduced in thermomechanical models of mountain building [Toussaint et al., 2004].

\subsection{Geometry of the Basal Decollement, Seismicity, and Thermal Structure}

[36] Our model favors a basal shear zone with a dip angle of $\sim 17^{\circ} \mathrm{E}$ extending to a depth of $\sim 30 \mathrm{~km}$ below the most internal portion of the orogen. This geometry is needed to reproduce the observed high peak metamorphic temperatures of $\sim 500^{\circ} \mathrm{C}$ in eastern TC. A different geometry, with a $9-10^{\circ} \mathrm{E}$ dipping decollement, has been proposed from relocated microseismicity in central Taiwan [Carena et al., 2002]. However, the idea that seismicity delineates the major decollement is questionable. In a similar context (Nepal Himalaya), it is well documented that seismicity correlates with zones of interseismic stress accumulation rather than with particular structures [e.g., Bollinger et al., 2004b]. We have compared in Figure 14 relocalized seismicity from 1991 to 1999 [Wu et al., 2007], prior to the 1999 Chi-Chi earthquake, with the thermal structure and decollement geometry obtained in this study. We do not observe any specific correlation between seismicity and the geometry of the proposed basal decollement. A clear seismic gap is observed below the high topography of the mountain belt along the northern and central transects. This suggests that topography may also control seismicity by influencing the general stress field. This idea is supported by a major change from NW-SE compression in western Taiwan to extension within the eastern regions of the mountain belt, as revealed from focal mechanisms and interseismic GPS data [Bos et al., 2003; Gourley et al., 2004; Kuochen et al., 2004]. A similar topographic control has already been proposed and modeled in the Himalayas of central Nepal [Bollinger et al., 2004b]. However, the seismic gap beneath the BS may also be thermally controlled, as already suggested by Lin [2002]. In fact inhibition of seismicity coincides reasonably with the $300-400^{\circ} \mathrm{C}$ isotherms (Figure 14), which are generally the temperatures assumed to mark the downdip limit of the seismogenic zone for quartzo-feldspathic rocks [Blanpied et al., 1991]. This is remarkable to the east of the HR, but also mostly below the TC and within the backstop, in the case of the southern and central transects. In the case of the northern transect, seismicity below the contact with the backstop occurs at predicted temperatures of up to $\sim 600^{\circ} \mathrm{C}$, well over the usually accepted cutoff temperature of $\sim 350^{\circ} \mathrm{C}$ for continental rocks. The complexity of the seismicity along the northern transect is probably related to 3-D effects due to the proximity of the Ryukyu trench (Figure 1).

[37] It should be recalled that our modeling setup implies that the underplating rate $V_{u}$ and the geometry of the decollement are interdependent because we assume that the footwall does not deform (Figure 6). It follows that the inferred geometry of the basal decollement strongly depends on this setup and might only roughly reflect reality. In the absence of any robust direct constraints on the structure of the wedge at depth the model described here should be seen only as a reasonable first-order approximation.

\subsection{Balancing Incoming and Outcoming Fluxes}

[38] Our thermokinematic model provides estimates of the fluxes of material in and out of the orogen. Predicted erosion rates range from $\sim 0.4 \mathrm{~mm} \mathrm{a}^{-1}$ for the $\mathrm{BS}$ to $\sim 6.1 \mathrm{~mm} \mathrm{a}^{-1}$ for the TC. For the last $1.5 \mathrm{Ma}$, this yields an average value of $\sim 3.2 \mathrm{~mm} \mathrm{a}^{-1}$ at the scale of the $\sim 96 \mathrm{~km}$ 

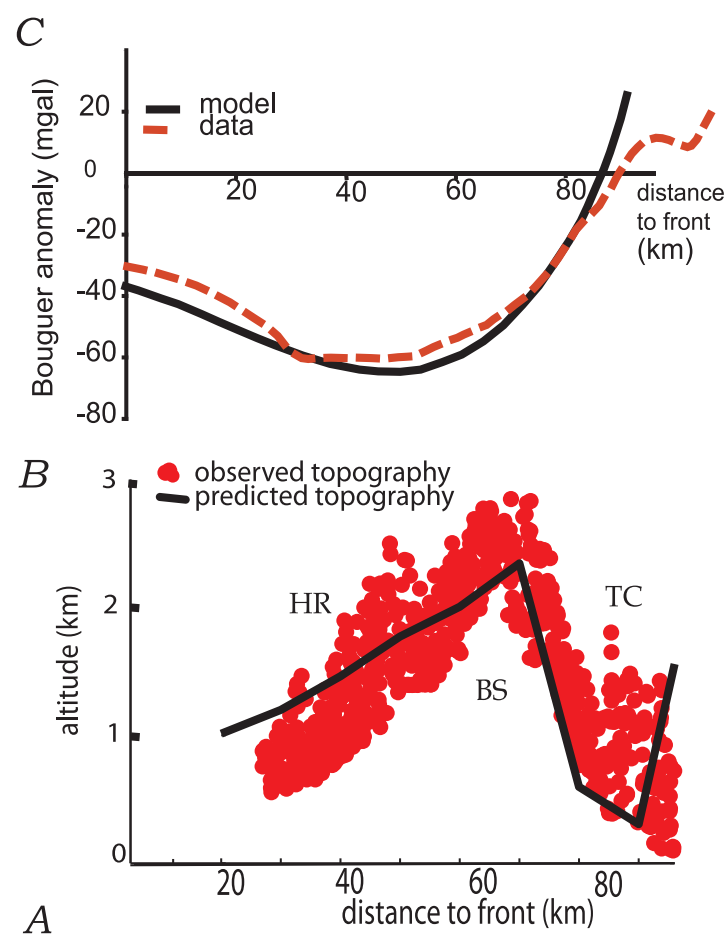

A

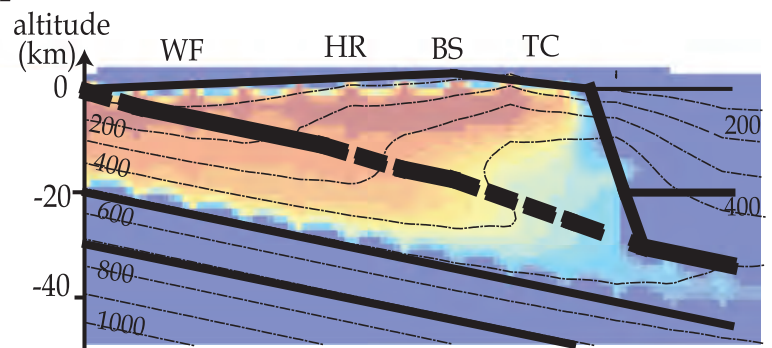

density

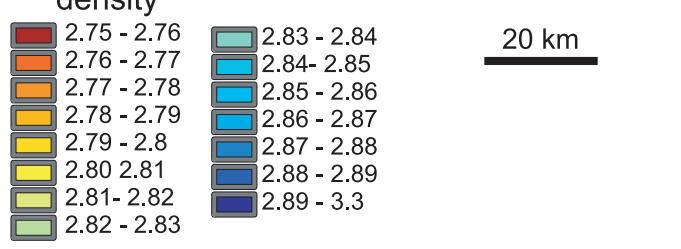

Figure 19. Predicted (a) density field, (b) topography, and (c) Bouguer anomaly along the northern transect. Densities are predicted for the chemical compositions detailed in Table 1 and for the P-T conditions computed in our model, using the procedures described by Bousquet et al. [1997]. The topography was determined from the densities computed in Figure 19a (black line) by assuming local isostasy and compensation within the asthenosphere (procedures described by Henry et al. [1997]). The observed topography (red dots) is taken within a $30 \mathrm{~km}$ wide swath across the northern transect (Figure 1). The Bouguer anomaly is computed from the density field shown in Figure 19a (black line) and is compared to the observed Bouguer anomaly [Yen et al., 1998] (red dashed line) obtained assuming a surface density of 2.76 for the topographic correction. See text for further details and discussions. wide mountain belt (Figure 7). A slightly lower average erosion rate of $\sim 3.1 \mathrm{~mm} \mathrm{a}^{-1}$ is calculated for the period before the widening of the underplating window below the $\mathrm{TC}, 1.5 \mathrm{Ma}$ ago. Erosion rate is at any point nearly equal to the local underplating rate $V_{u}$ because the topographic correction is minor, and because we have assumed steady state topography and vertical hinge lines (Figure 6). Our estimate of the average erosion rate is slightly lower than the value of $5.2 \mathrm{~mm} \mathrm{a}^{-1}$ obtained by Dadson et al. [2003] from river load over a period of $\sim 30$ a (suspended load and bed load). This short-term estimate may however not be directly comparable to the longer term value because of a possible strong variability related to discrete seismic and climatic events [e.g., Dadson et al., 2004]. By contrast, our estimated erosion rates are slightly higher than the average $2.3 \mathrm{~mm} \mathrm{a}^{-1}$ erosion rate derived from FT data on apatites and zircons [Fuller et al., 2006]. Our estimates are more accurate because of the larger thermometric and thermochronological data sets used in our analysis but also because Fuller et al. [2006] do not account for the exhumation of the HR units.

[39] From the geometry of our model (Figure 7), we predict that a thickness $h$ of $\sim 7 \mathrm{~km}$ of the underthrust material (crust and sedimentary sequences) participates to the growth of the mountain belt, so that $\sim 20-23 \mathrm{~km}$ of crust would be lost in subduction beneath the Philippine Sea Plate. This value is an upper estimate of the amount of underthrust crust probably lost in subduction, because the crustal thickness of the subducted Chinese passive margin may have been thinner in the past. Given the constant wedge width of $\sim 96-98 \mathrm{~km}$ over northern Taiwan, predicted erosion rates fully balance the material incorporated into the wedge, and yield incoming and outcoming fluxes of $\sim 300 \mathrm{~m}^{2} \mathrm{a}^{-1}$ per $\mathrm{m}$ of section along strike.

\subsection{Metamorphic Transformations, Subduction of Continental Crust, and Topography}

[40] The pressure and temperature fields computed from the model and the assumed initial chemical composition of the rocks forming the orogen (Table 1) are used to predict metamorphic facies and the distribution of material densities within the wedge (Figure 19a). Our approach follows the procedure proposed by Bousquet et al. [1997], which accounts for compressibility and thermal expansion (Table 1). These calculations assume that mineral assemblages attain at all time thermodynamic equilibrium independently of the P-T-t history and of the kinetics of metamorphic reactions. Results are illustrated in Figure 19a for the northern transect and densities appear roughly controlled by the thermal structure. Densities exceeding $\sim 3$ are found within the underthrust crust below the orogenic wedge because of its gradual densification (Figure 19a). This might explain why a significant amount of the underthrust crust does not participate to the growth of the orogenic wedge but is rather lost in subduction within the mantle. This is true not only for the lower crust but also for part of the upper crust of the underthrust plate. This densification at the base of the wedge can also account for the lack of a clear seismic Moho east of the central range [Kim et al., 2005; Lin, 2005; McIntosh et al., 2005; Shih et al., 1998; Yeh et al., 1998], as also observed and proposed in the case of other collisional orogens [Bousquet et al., 
1997; Goffé et al., 2003; Le Pichon et al., 1997]. From the density field, we compute the topography by assuming local isostasy and compensation in the asthenosphere. The details of these procedures are described elsewhere [Bousquet et al., 1997; Goffé et al., 2003; Henry et al., 1997]. This simple approach is able to reproduce the overall observed topography (Figure 19b), in particular the location of the highest elevations over the eastern $\mathrm{BS}$ and the lower topography over the higher grade TC. The Bouguer anomaly associated with the predicted density field was computed with Hypermag [Saltus and Blakely, 1995] (ftp:// ftpmusette.cr.usgs.gov/pub/saltus/hypermag/) and compared to the measured Bouguer anomaly of Yen et al. [1998] (Figure 19). For consistency between the two computations, the anomaly measurements were corrected for a surface density of 2.76 equivalent to the surface density of metasediments used for our calculations [Bousquet et al., 1997]. Overall, there is a good fit between the predicted and observed anomalies. However, there are some caveats here that are worth mentioning. Densities predicted at depth can be overestimated because mineralogy is in fact poorly developed in Taiwan. We checked that minerals used by Bousquet et al. [2005] to calculate their density grid in the case of metasediments are common within the Taiwan mountain belt [Beyssac et al., 2007]. On the other hand, this density grid is probably valid along the prograde path of rocks, but it probably underestimates shallow rock densities because it assumes instantaneous equilibration during cooling and exhumation. In Taiwan, complete equilibration during exhumation may not occur because of limiting kinetics [Beyssac et al., 2007]. These limitations are probably not critical in Taiwan because all computed P-T conditions are at most within the greenschist facies (Figure 17), and mineralogy is in fact not expected to vary much over these metamorphic facies [Bousquet et al., 1997]. Also, the density low observed below BS, which accounts in particular for the predicted topographic high, may still be correct because it is rather related to thermal expansion prevailing over compressibility at such P-T conditions [Bousquet et al., 2005, Figure 1b] rather than to a particular mineralogy.

[41] These results imply that topography is essentially compensated by local isostasy. This is consistent with the low elastic thickness of the underthrust plate estimated to be $\sim 10 \mathrm{~km}$ [Lin and Watts, 2002; Mouthereau and Petit, 2003] and with the observed inelastic yielding of the foreland basement [Chou and Yu, 2002]. Indeed, these elements indicate that flexural support is negligible in Taiwan. This example suggests that the density distribution resulting from metamorphism within an orogenic wedge has significant effects on the topography and morphology of the orogen [e.g., Goffé et al., 2003]. Such parameters ought to be taken into account in mechanical models of mountain building, in particular because metamorphism and densities are expected to affect the tectonic and therefore thermal response to unloading and erosion at the surface. Also, the good fit to the observed topography and Bouguer anomaly lends support to our modeling, and in particular indicates that our model geometry is viable.

\subsection{Reappraising Mountain Building in Taiwan}

[42] Although there is probably not a unique way of adjusting our model to the metamorphic and thermochronological data, our results allow for identifying a few key features that any model of mountain building in Taiwan should include. This study, together with the studies of the development of the foreland basin over the last $2 \mathrm{Ma}$ [Simoes and Avouac, 2006] and of the active deformation across the WF [Simoes et al., 2007a, 2007b], indicates that horizontal shortening is accommodated by slip on the most frontal faults of the WF, and that the incoming flux of material into the eroding orogen has been sustained essentially by underplating below the HR and TC. Shortening related to activation of internal faults, possibly resulting from out-of-sequence thrusting within the wedge [Tillman and Byrne, 1996], does not seem to have played a key role over the last $2 \mathrm{Ma}$ in the structural evolution and exhumation of the orogen. Our model differs from the kinematics predicted in models involving a homogeneous wedge growing primarily by frontal accretion. One reason for the departure from these models could be that the rheological layering due to the thermal structure and lithological variations may generate vertical strain gradients favoring underplating. Indeed, it has been shown from analogue experiments that the relative contribution of frontal accretion and underplating to the growth of an orogenic wedge depends on the layering of the underthrust crust [Konstantinovskaia and Malavieille, 2005]. In particular, these experiments show that the existence of a weak decollement level favors the formation of duplexes and a kinematics similar to the one proposed here. It is for instance possible that underplating below the HR is related to the presence of decollement levels inherited from the structural architecture of the passive margin, or that it results from duplexes formed at the transition from the brittleductile transition (Figure 14). In the case of the TC, duplexes may be structurally controlled (Figure 18) or may be related to the accretion and uplift along the backstop of material that has not become dense enough for subduction into the mantle (Figure 19). Finally, it is possible that underplating and surface processes contribute jointly to maintain an overcritical topography so that deviatoric stresses within the wedge remain too small to induce internal shortening.

\subsection{Solving the Temporal Evolution of the Mountain Belt: From Frontal Accretion to Underplating}

[43] Our model provides some idea of the thermal and kinematic history of the mountain belt over a relatively large period of time, from $\sim 6-7 \mathrm{Ma}$ to present. Indeed, it is adjusted to various data sets covering different temporal stages of exhumation, from burial and deep metamorphism as revealed by RSCM temperatures to the younger stages of cooling documented by low-temperature thermochronology. It turns out that some temporal changes in the kinematics of deformation are needed. Reconciling all the data requires in particular an increase in the incoming fluxes below the TC by about $1.5 \mathrm{Ma}$, modeled here as a widening of the underplating window (Figure 7). Such a scenario is supported independently by the observation of a sharp increase by 1 to $2 \mathrm{Ma}$ in the sediment supply into the basin that formerly flanked the Taiwan mountain belt to the east 
and that has now been incorporated within the CoR [Dorsey and Lundberg, 1988]. The widening of the underplating window below the TC $1.5 \mathrm{Ma}$ ago implies a change in the relative contribution of frontal accretion and underplating to orogenic growth. Before $1.5 \mathrm{Ma}$, only $\sim 20 \%$ of the incoming flux is absorbed by underplating beneath the TC. Before $4 \mathrm{Ma}$, i.e., before the onset of underplating below the HR, frontal accretion takes up $\sim 80 \%$ of the incoming material (Figure 15). Between $4 \mathrm{Ma}$ and $1.5 \mathrm{Ma}$, underplating beneath the HR contributes an additional $\sim 20 \%$ of the incoming flux. Over that period, frontal accretion is therefore still slightly dominant $(\sim 60 \%)$. Later on, from 1.5 $\mathrm{Ma}$ to present, underplating becomes the dominant mode of the growth of the orogenic wedge by accounting for $\sim 90 \%$ of the incoming flux ( $\sim 70 \%$ beneath the TC and $\sim 20 \%$ beneath the HR), reducing the contribution of frontal accretion to $\sim 10 \%$. Frontal accretion is in this case expected to essentially account for the growth of the WF. It should be noted that the validity of our kinematic assumption before 1.5 $\mathrm{Ma}$ and above all before $4 \mathrm{Ma}$ (relative to the northern transect) may be questioned. Indeed, it is possible that distributed shortening within the wedge may have been significant at the time frontal accretion was dominant. In this case, it is possible that shortening across the HR, as documented from finite strain measurements, occurred prior to $4 \mathrm{Ma}$. Distributed shortening within the wedge would have taken place if crustal thickening due to underplating beneath the HR and the TC was insufficient to maintain the wedge in an overcritical state (Figure 7). Most probably this caveat is not a major issue for our model, and the need for an increase in the contribution of underplating is probably a robust finding of our analysis. Indeed, if shortening of the wedge is underestimated, the amount of underplating needed to explain the observed exhumation is expected to be overestimated.

[44] What are the mechanisms responsible for the changes in the mode of orogenic growth by $4 \mathrm{Ma}$ and 1.5 Ma? The coincidence with the onset of Pleistocene glacial periods suggests that it might represent a tectonic response to a climate-driven increase in erosion rates. It is thought that climate, through erosion, may interplay with the mechanics of mountain building [Avouac and Burov, 1996; Molnar and England, 1990] and affect the exhumation and structural evolution of a mountain range [Willett, 1999]. Also, the last 1.1 to $1.5 \mathrm{Ma}$ coincide in Taiwan with the widespread deposition of the thick Toukoshan conglomerates in the foreland basin. Similar thick conglomerate deposits are found along the piedmont of many mountain ranges and are often attributed to a climate-driven increase in erosion [e.g., Molnar, 2004; Molnar and England, 1990]. However, the conglomeratic deposits may as well simply reflect the most proximal foreland sediments, and equivalent facies of older formations may not be presently visible in the basin because they have been remobilized within the range. In any case, if the tectonic change $1.5 \mathrm{Ma}$ ago were of climatic origin, it should have affected the whole mountain belt and not only the exhumation of the TC. An alternative explanation is that the temporal changes may have been governed by the architecture of the underthrust passive margin (Figure 18), by influencing the partitioning between frontal accretion and underplating as observed in the analogue experiments also of Konstantinovskaia and
Malavieille [2005]. These analogue experiments also show that the contribution of underplating increases with cumulated shortening, so that our observations may simply reflect the natural way a collisional orogen evolves over time.

\section{Conclusion}

[45] This study presents an attempt to describe the evolution of the Taiwan orogen over the last few Ma by taking into account available kinematic, metamorphic, and thermochronological constraints. It shows that thermokinematic modeling is a powerful approach to develop and test models of mountain building by comparing them to such a wide variety of data. We show in the case of Taiwan that such data can be reconciled with a simple model assuming that all shortening has been absorbed at the front of the orogen over the last $1.5 \mathrm{Ma}$ and that the input of material into the orogenic wedge has been mainly sustained (up to $\sim 90 \%$ ) by underplating. Underplating is heterogeneous and seems to occur through the formation of duplexes below the HR and the TC. The kinematics of the Taiwan orogen probably went through a major reorganization $\sim 1.5 \mathrm{Ma}$ ago with an increase in the volume of underplated material beneath the TC, and also $4 \mathrm{Ma}$ ago as exhumation of the HR units initiated. These adjustments might be due to changes in external forcing factors (climate in particular) or to the characteristics of the underthrust Chinese passive margin. In general, the initial architecture of the passive margin has probably been a cause for complexities in the development of the orogen, both in space or time, that are not accounted for by the simple model described in this paper. The balance between incoming and outgoing fluxes requires a large amount of crustal subduction, allowed by the densification of the underthrust crustal and sedimentary sequences. Metamorphic changes, the influence of surface processes on the thermal structure and stress redistribution appear to be key factors to explain the dynamics of mountain building in Taiwan.

[46] Acknowledgments. M.S. wishes to thank Pierre Henry and Laurent Bollinger for introducing her to the FEAP program used in modeling the evolution of the Taiwan mountain belt. Heat flow data were kindly provided by Kuo-Fong Ma and T.-R. A. Song. We are also grateful to Horng-Yuan Yen for providing Bouguer anomaly data corrected for the surface density of 2.76 and to Yi-Min $\mathrm{Wu}$ for providing relocalized seismicity data. This manuscript improved thanks to the comments by Steven Kidder and the thoughtful discussions with John Suppe. It also benefited from the constructive reviews of Tim Byrne, Don Fisher, and Jacques Malavieille, as well as from the comments of the AE Gregory Moore. This study has been partly funded by the Gordon and Betty Moore Foundation. This is Caltech Tectonics Observatory contribution 73

\section{References}

Avouac, J. P. (2003), Mountain building, erosion and the seismic cycle in the Nepal Himalaya, Adv. Geophys., 46, doi:10.1016/S0065-2687(03)46001-9.

Avouac, J. P., and E. B. Burov (1996), Erosion as a driving mechanism of intracontinental mountain growth, J. Geophys. Res., 101, 17,747-17,769.

Barr, T. D., and F. A. Dahlen (1989), Brittle frictional mountain building: 2. Thermal structure and heat budget, J. Geophys. Res., 94, 3923-3947. Barr, T. D., F. A. Dahlen, and D. C. McPhail (1991), Brittle frictional mountain building: 3. Low-grade metamorphism, J. Geophys. Res., 96, $10,319-10,338$

Beyssac, O., B. Goffé, C. Chopin, and J.-N. Rouzaud (2002), Raman spectra of carbonaceous material in metasediments: A new geothermometer, J. Metamorph. Geol., 20, 859-871.

Beyssac, O., M. Simoes, J. P. Avouac, K. A. Farley, Y.-G. Chen, Y.-C. Chan, and B. Goffé (2007), Late Cenozoic metamorphic evolution and 
exhumation of Taiwan, Tectonics, 26, TC6001, doi:10.1029/ 2006TC002064.

Blanpied, M. L., D. A. Lockner, and J. D. Byerlee (1991), Fault stability inferred from granite sliding experiments at hydrothermal conditions, Geophys. Res. Lett., 18, 609-612.

Bollinger, L., J. P. Avouac, O. Beyssac, E. J. Catlos, T. M. Harrison, M. Grove, B. Goffé, and S. Sapkota (2004a), Thermal structure and exhumation history of the Lesser Himalaya in central Nepal, Tectonics, 23, TC5015, doi:10.1029/2003TC001564.

Bollinger, L., J. P. Avouac, R. Cattin, and M. R. Pandey (2004b), Stress buildup in the Himalaya, J. Geophys. Res., 109, B11405, doi:10.1029/2003JB002911.

Bollinger, L., P. Henry, and J. P. Avouac (2006), Mountain building in the Nepal Himalaya: Thermal and kinematic model, Earth Planet. Sci. Lett., 244, 58-71.

Bos, A. G., W. Spakman, and M. C. J. Nyst (2003), Surface deformation and tectonic setting of Taiwan inferred from a GPS velocity field, J. Geophys. Res., 108(B10), 2458, doi:10.1029/2002JB002336.

Bousquet, R., B. Goffé, P. Henry, X. Le Pichon, and C. Chopin (1997), Kinematic, thermal and petrological model of the Central Alps: Lepontine metamorphism in the upper curst and eclogitisation of the lower crust, Tectonophysics, 273, 105-127.

Bousquet, R., B. Goffé, X. Le Pichon, C. de Capitani, C. Chopin, and P. Henry (2005), Comment on "Subduction factory: 1. Theoretical mineralogy, densities, seismic wave speeds, and $\mathrm{H}_{2} \mathrm{O}$ contents" by Bradley R. Hacker, Geoffrey A. Abers, and Simon M. Peacock, J. Geophys. Res., 110, B02206, doi:10.1029/2004JB003450.

Braun, J. (2002), Quantifying the effect of recent relief changes on ageelevation relationships, Earth Planet. Sci. Lett., 200, 331-343.

Byrne, T. B., and C.-S. Liu (2002), Introduction to the geology and geophysics of Taiwan, in Geology and Geophysics of an Arc-Continent Collision, Taiwan, edited by T. B. Byrne and C.-S. Liu, Spec. Pap. Geol. Soc. Am., 358, V-VIII.

Carena, S., J. Suppe, and H. Kao (2002), Active detachment of Taiwan illuminated by small earthquakes and its control of first-order topography, Geology, 30, 935-938.

Chang, H. C. (1989), Radioactivity and heat generation of rocks in the Taiwan region, Ph.D. thesis, 159 pp, Natl. Central Univ., Chung-Li, Taiwan.

Chapple, W. M. (1978), Mechanics of thin-skinned fold-and-thrust belts, Geol. Soc. Am. Bull., 89, 1189-1198.

Chou, Y.-W., and H.-S. Yu (2002), Structural expressions of flexural extension in the arc-continent collisional foredeep of western Taiwan, in Geology and Geophysics of an Arc-Continent Collision, Taiwan, edited by T. B. Byrne and C.-S. Liu, Spec. Pap. Geol. Soc. Am., 358, 1-12.

Clark, M. B., D. M. Fisher, C.-Y. Lu, and C.-H. Chen (1993), Kinematic analyses of the Hsueshan range, Taiwan: A large-scale pop-up structure, Tectonics, 12, 205-217.

Crespi, J. M., Y.-C. Chan, and M. S. Swaim (1996), Synorogenic extension and exhumation of the Taiwan hinterland, Geology, 24, 247-250.

Dadson, S. J., et al. (2003), Links between erosion, runoff variability and seismicity in the Taiwan orogen, Nature, 426, 648-651.

Dadson, S. J., et al. (2004), Earthquake-triggered increase in sediment delivery from an active mountain belt, Geology, 32, 733-736.

Dahlen, F. A., and T. D. Barr (1989), Brittle frictional mountain building 1. Deformation and mechanical energy budget, J. Geophys. Res., 94, 3906-3922.

Davis, D., J. Suppe, and F. A. Dahlen (1983), Mechanics of fold-and-thrust belts and accretionary wedges, J. Geophys. Res., 88, 1153-1172.

Dorsey, R. J., and N. Lundberg (1988), Lithofacies analysis and basin reconstruction of the Plio-Pleistocene collisional basin, Coastal Range of eastern Taiwan, Acta Geol. Taiwan, 26, 57-132.

Dunlap, W. J., G. Hirth, and C. Teyssier (1997), Thermomechanical evolution of a ductile duplex, Tectonics, 16, 983-1000.

Ernst, W. G. (1983), Mineral paragenesis in metamorphic rocks exposed along Tailuko Gorge, central Mountain-range, Taiwan, J. Metamorph. Geol., 1, 305-329.

Ernst, W. G., and B. M. Jahn (1987), Crustal accretion and metamorphism in Taiwan, a post-Paleozoic mobile belt, Philos. Trans. R. Soc. London, Ser. A, 321, 129-161.

Faure, M., C. Y. Lu, and H. T. Chu (1991), Ductile deformation and Miocene nappe-stacking in Taiwan related to motion of the Philippine Sea Plate, Tectonophysics, 198, 95-105.

Fisher, D. M., C. Y. Lu, and H. T. Chu (2002), Taiwan Slate Belt: Insights into the ductile interior of an arc-continent collision, in Geology and Geophysics of an Arc-Continent Collision, Taiwan, edited by T. B. Byrne and C.-S. Liu, Spec. Pap. Geol. Soc. Am., 358, 93-106.

Fisher, D. M., S. Willett, Y. En-Chao, and M. B. Clark (2007), Cleavage fronts and fans as reflections of orogen stress and kinematics in Taiwan, Geology, 35, 65-68.
Fuller, C. W., S. D. Willett, D. M. Fisher, and C. Y. Lu (2006), A thermomechanical wedge model of Taiwan constrained by fission-track thermochronometry, Tectonophysics, 425, 1-24.

Goffé, B., R. Bousquet, P. Henry, and X. Le Pichon (2003), Effect of the chemical composition of the crust on the metamorphic evolution of orogenic wedges, J. Metamorph. Geol., 21, 123-141.

Gourley, J. R., T. Byrne, F. T. Wu, Y.-C. Chan, S. Yu, and L. Kuo (2004), Along strike GPS and seismic constraints on extension in eastern Central Range, Eos Trans. AGU, 85(47), Fall Meet. Suppl., Abstract T41C-1221.

Hansen, F. D., and N. L. Carter (1982), Creep of selected crustal rocks at $1000 \mathrm{MPa}$, Eos Trans. $A G U, 63,437$.

Henry, P., X. Le Pichon, and B. Goffé (1997), Kinematic, thermal and petrological model of the Himalayas: Constraints related to metamorphism within the underthrust Indian crust and topographic elevation, Tectonophysics, 273, 31-56.

Hetland, E. A., and F. T. Wu (1998), Deformation of the Philippine Sea Plate under the coastal range, Taiwan: Results from an offshore-onshore seismic experiment, Terr. Atmos. Oceanic Sci., 9, 363-378.

Hickman, J. B., D. V. Wiltschko, J.-H. Hung, P. Fang, and Y. Bock (2002), Structure and evolution of the active fold-and-thrust belt of southwestern Taiwan from Global Positioning System analysis, in Geology and Geophysics of an Arc-Continent Collision, Taiwan, edited by T. B. Byrne and C.-S. Liu, Spec. Pap. Geol. Soc. Am., 358, 75-92.

Ho, C. S. (1986), A synthesis of the geologic evolution of Taiwan, Tectonophysics, 125, 1-16.

Ho, C. S. (1988), An introduction to the geology of Taiwan-Explanatory Text of the Geologic Map of Taiwan, 2nd ed., 192 pp., Central Geol. Surv., Taipei.

Huerta, A. D., L. H. Royden, and K. V. Hodges (1998), The thermal structure of collisional orogens as a response to accretion, erosion, and radiogenic heating, J. Geophys. Res., 103, 15,287-15,302.

Hung, J.-H., D. V. Wiltschko, H.-C. Lin, J. B. Hickman, P. Fang, and Y. Bock (1999), Structure and motion of the southwestern Taiwan fold and thrust belt, Terr. Atmos. Oceanic Sci., 10, 543-568.

Hwang, W.-T., and C.-Y. Wang (1993), Sequential thrusting model for mountain building: Constraints from geology and heat flow of Taiwan, J. Geophys. Res., 98, 9963-9973.

Kim, K. H., et al. (2005), Three-dimensional $V_{p}$ and $V_{s}$ structural models associated with the active subduction and collision tectonics in the Taiwan region, Geophys. J. Int., 162, 204-220.

Konstantinovskaia, E., and J. Malavieille (2005), Erosion and exhumation in accretionary orogens: Experimental and geological approaches, Geochem. Geophys. Geosyst., 6, Q02006, doi:10.1029/2004GC000794.

Kuochen, H., Y. Wu, Y. Chen, R. Chen, and Y. Kuo (2004), Seismogenic structures in Hualien region, Eastern Taiwan, Eos Trans. AGU, 85(47), Fall Meet. Suppl., Abstract T11D-1302.

Lee, C. R., and W. T. Cheng (1986), Preliminary heat flow measurements in Taiwan, paper presented at Fourth Circum-Pacific Energy and Mineral Resources Conference, Circum-Pac. Counc. for Energy and Miner. Resour., Singapore.

Lee, J. C., J. Angelier, and H. T. Chu (1997), Polyphase history and kinematics of a complex major fault zone in the northern Taiwan mountain belt: The Lishan fault, Tectonophysics, 274, 97-115.

Le Pichon, X., P. Henry, and B. Goffé (1997), Uplift of Tibet: From eclogites to granulites-Implications for the Andean plateau and the Variscan belt, Tectonophysics, 273, 57-76.

Lin, A. T., and A. B. Watts (2002), Origin of the West Taiwan Basin by orogenic loading and flexure of a rifted continental margin, J. Geophys. Res., 107(B9), 2185, doi:10.1029/2001JB000669.

Lin, A. T., A. B. Watts, and S. P. Hesselbo (2003), Cenozoic stratigraphy and subsidence history of the South China Sea margin in the Taiwan region, Basin Res., 15, 453-478.

Lin, C. H. (1998), Tectonic implications of an aseismic belt beneath eastern Central Range of Taiwan: Crustal subduction and exhumation, J. Geol. Soc. China, 41, 441-460.

Lin, C. H. (2002), Active continental subduction and crustal exhumation: The Taiwan orogeny, Terra Nova, 14, 281-287.

Lin, C.-H. (2005), Identification of mantle reflections from a dense linear seismic array: Tectonic implications to the Taiwan orogeny, Geophys. Res. Lett., 32, L06315, doi:10.1029/2004GL021814.

Liou, J. G., C. O. Ho, and T. P. Yen (1975), Petrology of some glaucophane schists and related rocks from Taiwan, J. Petrol., 16, 80-109.

Liu, T.-K. (1982), Tectonic implications of fission track ages from the Central Range, Taiwan, Proc. Geol. Soc. China, 25, 22-37.

Liu, T.-K., S. Hsieh, Y.-G. Chen, and W.-S. Chen (2001), Thermokinematic evolution of the Taiwan oblique-collision mountain belt as revealed by zircon fission-track dating, Earth Planet. Sci. Lett., 186, $45-56$. 
Lo, C.-H., and T. C. Onstott (1995), Rejuvenation of K-Ar systems for minerals in the Taiwan mountain belt, Earth Planet. Sci. Lett., 131, $71-98$

Lo, C. H., and T.-F. Yui (1996), 40Ar/39Ar dating of high-pressure rocks in the Tananao basement complex, Taiwan, J. Geol. Soc. China, 39, 13-30.

Malavieille, J., and G. Trullenque (2007), Consequences of continental subduction on forearc basin and accretionary wedge deformation in SE Taiwan: Insights from analogue modeling., Tectonophysics, in press.

Malavieille, J., et al. (2002), Arc-continent collision in Taiwan: New marine observations and tectonic evolution, in Geology and Geophysics of an Arc-Continent Collision, Taiwan, edited by T. B. Byrne and C.-S. Liu, Spec. Pap. Geol. Soc. Am., 358, 189-213.

McIntosh, K., Y. Nakamura, T.-K. Wang, R. C. Shih, A. Chen, and C. S Liu (2005), Crustal-scale seismic profiles across Taiwan and the western Philippine Sea, Tectonophysics, 401, 23-54.

Molnar, P. (2004), Late Cenozoic increase in accumulation rates of terrestrial sediment: How might climate change have affected erosion rates?, Annu. Rev. Earth Planet. Sci., 32, 67-89.

Molnar, P., and P. England (1990), Late Cenozoic uplift of mountain ranges and global climate change: Chicken or egg?, Nature, 346, 29-34.

Mouthereau, F., and C. Petit (2003), Rheology and strength of the Eurasian continental lithosphere in the foreland of the Taiwan collision belt: Constraints from seismicity, flexure, and structural styles, J. Geophys. Res., 108(B11), 2512, doi:10.1029/2002JB002098.

Mouthereau, F., O. Lacombe, B. Deffontaines, J. Angelier, and S. Brusset (2001), Deformation history of the southwestern Taiwan foreland thrust belt: Insights from tectono-sedimentary analyses and balanced crosssections, Tectonophysics, 333, 293-322.

Powell, L. K. (2003), Feedback between erosion and fault reactivation in the Puli Basin: Hsueshan belt of central Taiwan, Master thesis, 61 pp., Univ. of Colo., Boulder.

Pulver, M. H., J. M. Crespi, and T. B. Byrne (2002), Lateral extrusion in a transpressional collision zone: An example from the pre-Tertiary metamorphic basement of Taiwan, in Geology and Geophysics of an Arc-Continent Collision, Taiwan, edited by T. B. Byrne and C.-S. Liu, Spec. Pap. Geol. Soc. Am., 358, 107-120.

Rao, C. T., and P. L. Li (1994), Heat flow in the Zhujiangkou Basin (in Chinese with English abstract), Oil Eastern South China Sea, 15, 10-18

Reiners, P. W., T. L. Spell, S. Nicolescu, and K. A. Zanetti (2004), Zircon (U-Th)/He thermochronometry: He diffusion and comparisons with ${ }^{40} \mathrm{Ar}{ }^{39} \mathrm{Ar}$ dating, Geochim. Cosmochim. Acta, 68, 1857-1887.

Saltus, R. W., and R. J. Blakely (1995), HYPERMAG: An interactive, 2 - and 2.5-dimensional gravity and magnetic modeling program, version 3.5, U.S. Geol. Surv., Reston, Va.

Sella, G. F., T. H. Dixon, and A. Mao (2002), REVEL: A model for Recent plate velocities from space geodesy, J. Geophys. Res., 107(B4), 2081, doi:10.1029/2000JB000033.

Shih, R. C., C. H. Lin, H. L. Lai, Y. H. Yeh, B. S. Huang, and H. Y. Yen (1998), Preliminary crustal structures across central Taiwan from modeling of the onshore/offshore wide-angle seismic data., Terr. Atmos. Oceanic Sci. 9, 317-328.

Shyu, J. B.H., K. Sieh, J.-P. Avouac, W.-S. Chen, and Y.-G. Chen (2006a), Millennial slip rate of the Longitudinal Valley fault from river terraces: Implications for convergence across the active suture of eastern Taiwan, J. Geophys. Res., 111, B08403, doi:10.1029/2005JB003971.

Shyu, J. B.H., K. Sieh, Y.-G. Chen, and L.-H. Chung (2006b), Geomorphic analysis of the Central Range fault, the second major active structure of the Longitudinal Valley suture, eastern Taiwan, Geol. Soc. Am. Bull., 118, $1447-1462$

Simoes, M., and J. P. Avouac (2006), Investigating the kinematics of mountain building in Taiwan from the spatiotemporal evolution of the foreland basin and western foothills, J. Geophys. Res., 111, B10401, doi:10.1029/2005JB004209.

Simoes, M., J. P. Avouac, and Y.-G. Chen (2007a), Slip rates on the Chelungpu and Chushiang thrust faults inferred from a deformed strath terrace along the Dungpuna river, west central Taiwan, J. Geophys. Res., 112, B03S10, doi:10.1029/2005JB004200.

Simoes, M., J. P. Avouac, Y.-G. Chen, A. K. Singhvi, C.-Y. Wang, M. Jaiswal, Y.-C. Chan, and S. Bernard (2007b), Kinematic analysis of the Pakuashan fault tip fold, west central Taiwan: Shortening rate and age of folding inception, J. Geophys. Res., 112, B03S14, doi:10.1029/2005JB004198.

Song, A. T.-R., and K.-F. Ma (2002), Estimation of the thermal structure of a young orogenic belt according to a model of whole-crust thickening, in
Geology and Geophysics of an Arc-Continent Collision, Taiwan, edited by T. B. Byrne and C.-S. Liu, Spec. Pap. Geol. Soc. Am., 358, 121-136. Stanley, R. S., L. B. Hill, H. C. Chang, and H. N. Hu (1981), A transect through the metamorphic core of the Central Mountains, Taiwan, Mem. Geol. Soc. China, 4, 443-473.

Suppe, J. (1980), Imbricated structure of Western Foothills Belt, south central Taiwan, Pet. Geol. Taiwan, 17, 1-16.

Suppe, J. (1981), Mechanics of mountain building and metamorphism in Taiwan, Mem. Geol. Soc. China, 4, 67-89.

Suppe, J. (1984), Kinematics of arc-continent collision, flipping of subduction, and back-arc spreading near Taiwan, Mem. Geol. Soc. China, 6, 21-33.

Suppe, J., Y. Wang, J. G. Liou, and W. G. Ernst (1976), Observation of some contacts between basement and Cenozoic cover in the Central Mountains, Taiwan, Proc. Geol. Soc. China, 7, 59-70.

Taylor, S. M., and S. M. McLennan (1985), The Continental Crust: Its composition and Evolution, Blackwell, Oxford, U. K.

Teng, L. S. (1992), Geotectonic evolution of Tertiary continental margin basins of Taiwan, Pet. Geol. Taiwan, 27, 1-19.

Teng, L. S., et al. (1991), Tectonic aspects of the Paleogene depositional basin of northern Taiwan, Proc. Geol. Soc. China, 34, 313-336.

Tillman, K. S., and T. B. Byrne (1995), Kinematic analysis of the Taiwan Slate Belt, Tectonics, 14, 322-341.

Tillman, K. S., and T. B. Byrne (1996), Out-of-sequence thrusting in the Taiwan slate belt, J. Geol. Soc. China, 39, 189-208.

Toussaint, G., E. Burov, and J.-P. Avouac (2004), Tectonic evolution of a continental collision zone: A thermomechanical numerical model, Tectonics, 23, TC6003, doi:10.1029/2003TC001604.

Tsao, S. J. (1996), The geological significance of illite crystallinity, zircon fission-track ages and K-Ar ages of metasedimentary rocks of the Central Range, Ph.D. thesis, 272 pp., Natl. Taiwan Univ., Taipei, Taiwan.

Turcotte, D. L., and G. Schubert (2002), Geodynamics, 2nd ed., 456 pp., Cambridge Univ. Press, Cambridge, U. K.

Willett, S. D. (1999), Orogeny and topography: The effects of erosion on the structure of mountain belts, J. Geophys. Res., 104, 28,957-28,981.

Willett, S. D., and M. T. Brandon (2002), On steady-states in mountain belts, Geology, 30, 175-178.

Willett, S. D., C. Beaumont, and P. Fullsack (1993), Mechanical model for the tectonics of doubly vergent compressional orogens, Geology, 21, $371-374$

Willett, S. D., R. Slingerland, and N. Hovius (2001), Uplift, shortening, and steady-state topography in active mountain belts, Am. J. Sci., 301, 455-485.

Willett, S. D., D. M. Fisher, C. W. Fuller, Y. En-Chao, and L. Chia-Yu (2003), Erosion rates and orogenic-wedge kinematics in Taiwan inferred from fission-track thermochronometry, Geology, 31, 945-948.

Wu, Y.-M., C.-H. Chang, L. Zhao, J. B.H. Shyu, Y.-G. Chen, K. Sieh, and J.-P. Avouac (2007), Seismic tomography of Taiwan: Improved constraints from a dense network of strong motion stations, J. Geophys. Res., 112, B08312, doi:10.1029/2007JB004983.

Yang, C.-C. (2007), Seismogenic structure of the Chiayi-Tainan area and the long-term slip rates of frontal thrust faults in southwestern Taiwan, 125 pp, Natl. Taiwan Univ., Taipei.

Yeh, Y. H., et al. (1998), Onshore/offshore wide-angle deep seismic profiling in Taiwan, Terr. Atmos. Oceanic Sci., 9, 301-316.

Yen, H. Y, Y. H. Yeh, and F. T. Wu (1998), Two-dimensional crustal structures of Taiwan from gravity data, Tectonics, 17, 104-111.

Yue, L.-F., J. Suppe, and J.-H. Hung (2005), Structural geology of a classic thrust belt earthquake: The 1999 Chi-Chi earthquake Taiwan $\left(M_{w}=7.6\right)$, J. Struct. Geol., 27, 2058-2083.

Zhou, D., H.-S. Yu, H.-H. Xu, X.-B. Shi, and Y.-W. Chou (2003), Modeling of thermo-rheological structure of lithosphere under the foreland basin and mountain belt of Taiwan, Tectonophysics, 374, 115-134

Zienkiewicz, O. C., and R. L. Taylor (1989), The Finite-Element Method, McGraw-Hill, New York.

J. P. Avouac and K. A. Farley, Tectonics Observatory, California Institute of Technology, Pasadena, CA 91125, USA.

O. Beyssac and B. Goffé, Laboratoire de Géologie, ENS, CNRS, 24 rue Lhomond, F-75005 Paris, France.

Y.-G. Chen, Department of Geosciences, National Taiwan University, No. 1, Sec. 4th, Roosevelt Road, Taipei 106, Taiwan.

M. Simoes, IPGP, Université Paris 7, CNRS, 4 place Jussieu, F-75252 Paris Cedex, France. (simoes@ipgp.jussieu.fr) 